\title{
The Shape and Structure of the 'Usable Past': An Empirical Analysis of the use of Precedent in International Adjudication
}

\author{
Niccolò Ridi*
}

\begin{abstract}
How do international adjudicators use precedent? This question has been addressed several times in the literature, but doctrinal accounts have generally failed to consider the aggregate dimension of the phenomenon. This article seeks to provide an alternative outlook, by offering a large-scale computational analysis of the body of jurisprudence of three international fora (the ICJ, the WTO Appellate Body and investment arbitration tribunals) and comparing their citation patterns with those of other judicial bodies-national and international. Building on a very large dataset (comprising over 200,000 citations), it employs network analysis tools to measure the evolution of international law citation networks. It then unpacks this emerging complexity by considering what, in a precedent, holds 'citing value', bighlighting the expansion of the range of precedential resources as well as the consecration of established authorities. Finally, the article considers three examples of computational analysis of citations to precedent in order to better gauge the level of engagement with the past.
\end{abstract}

\section{Introduction}

When Judge Shahabuddeen delivered his classic lectures on Precedent in the World Court, the panorama of international dispute settlement looked simpler than it does today. ${ }^{1}$ Though neither the International Court of Justice (ICJ) nor the several interstate arbitration tribunals then in activity could be characterised as dormant, ${ }^{2}$ and several regional courts were in operation, international adjudicators were fewer, and the bulk and scope of their jurisprudence certainly less overwhelming. A question such as the one he addressed ('what is the nature and authority of precedent before the ICJ?') could more easily be tackled with the adoption of a purely doctrinal and qualitative methodology. Two decades later, any scholar interested in the same question would have to confront a much different scenario-one, it is submitted, that requires the adoption of different approaches.

As international law has gone on to become a heavily judicialized space, different actors have developed tools to improve their general cognition of it: databases have replaced the law reports that had, in their day, supplanted the 'Martens-style' treaty collections. ${ }^{3}$ And yet, international law knows neither Shepard's Citations

\footnotetext{
${ }^{*}$ LLB/MA (University of Florence); LLM (Cantab); PhD (King's College London); Lecturer, University of Liverpool School of Law; Visiting Lecturer, The Dickson Poon School of Law, King's College London.

${ }^{1}$ Shahbuddeen's monograph builds on his 1994 Lauterpacht Lectures. See Precedent in the World Court (Cambridge University Press 1996).

${ }^{2}$ Christine Gray and Benedict Kingsbury, 'Developments in Dispute Settlement: Inter-State Arbitration Since 1945' (1993) 63 British Yearbook of International Law 97.

3 Benedict Kingsbury, 'International Courts: Uneven Judicialisation in Global Order' in James Crawford, Martti Koskenniemi and Surabhi Ranganathan (eds), The Cambridge Companion to International Law (Cambridge University Press 2012); On the proliferation and merits of databases on international law, see 'EJIL: Talk! - Do We Need Another Database of International Law Documents?' <https://www.ejiltalk.org/do-we-need-another-database-of-international-law-documents/> accessed 26 March 2018.
} 
nor Westlaw: there are thus no widely accepted tools and schemata to discover whether a case has been endorsed, distinguished, or 'overruled', so to speak, by subsequent adjudicators. ${ }^{4}$ What is more, scholarswho often long for a system — tend to focus on landmark cases, rather than the aggregate: as 'grammarians' of the international legal system, ${ }^{5}$ they work as tirelessly as the punctilious 'purifiers' of Borges' Library of Babel, parsing the meaningful content from what they may perceive to be inevitable and endless gibberish. ${ }^{6}$ It is an open question, however, whether adjudicators agree with scholarly assessment of their output. ${ }^{7}$

The problem of precedent in international adjudication exacerbates these delicate methodological problems. Doctrinal studies may restrict themselves to identifying specific case studies or selecting a manageable sample, building on what is perceived as strong anecdotal evidence on the development of citation practices. Yet,. Though their merits of close forensic analyses of what constructs and justifications are invoked when negotiating an approach to the past or the other are readily acknowledged, they cannot capture the complexity of so sizeable a phenomenon. Moreover, reliance on what adjudicators say, rather than $d o$, may be counterproductive in the context of the accurate mapping of a phenomenon whose importance also lies in its quantitative measurability.

In this light, this study eschews the orthodox—evading, to start with, any discussion of Article 38(1)(d) and 59 of the ICJ Statute and equivalent provisions. Rather, it examines the scope and evolution of the citation practices of international adjudicators, with a view to unearthing latent features and patterns and shedding light on their understanding of authority from the past. To do so, it employs computational analysis tools to accurately examine an unprecedented number of citations to precedent by international adjudicators, and further contextualizes the findings by providing a comparison with analogous data relating to other international and national courts. Navigating through the network of international precedents will offer a bird's-eye view of the 'usable past'. ${ }^{8}$ More fundamentally, it highlights the complexity and relationality that qualify the law and the 'webs' it creates, ${ }^{9}$ as well as its perception by its constituencies.

The exposition will move as follows: Part I ties the present endeavour to previous studies on citations in the law; Part II will offer a high-level analysis and measurement of the main citation networks of international adjudicators, investigating the patterns that emerge from these citation practices; Part III will provide a more granular approach, breaking down citations to the propositions they stand for; Part IV sheds additional light on international adjudicators' citation patterns by offering a comparison with other dispute settlement mechanisms that apply international law to far lesser extent, but which are often controlled by international law practitioners; Part V engages in a content and tone analysis of the statements containing citations to precedent; finally, an assessment is offered.

\footnotetext{
${ }^{4}$ For a history of American legal citation indexes see Patti Ogden, “'Mastering the Lawless Science of Our Law”: A Story of Legal Citation Indexes' [1993] Journal Articles < https://scholarship.law.nd.edu/law_faculty_scholarship/118>.

${ }^{5}$ Gleider Hernández, 'The Responsibility of the International Legal Academic: Situating the Grammarian Within the "Invisible College" in Jean dAspremont and others (eds), International Law as a Profession (Cambridge University Press 2017) 161-162 <https://www.cambridge.org/core/product/identifier/9781316492802\%23CN-bp-6/type/book_part> accessed 25 July 2018.

${ }^{6}$ Jorge Luis Borges, El jardin de senderos que se bifurcan (Sur 1942).

${ }^{7}$ See Sondre Torp Helmersen, 'Scholarly-Judicial Dialogue in International Law' (2017) 16 The Law \&amp; Practice of International Courts and Tribunals 464.

8 The reference is to Van Wyck Brooks's essay 'On Creating a Usable Past' The Dial (4 November 1918) 337; The metaphor is sometimes used in the context of precedent, but its source is almost never acknolwedged. See for example Neil Duxbury, The Nature and Authority of Precedent (CUP 2008) 1-30; Gerald J Postema, 'Some Roots of Our Notion of Precedent' (1987) 9 Precedent in Law 15; On the legacy of Brooks's essay see David Lowenthal, The Past Is a Foreign Country - Revisited (Cambridge University Press 2015) 497.

9 Thomas A Smith, ‘The Web of Law’ (2007) 44 San Diego L. Rev. 309.
} 


\section{Measuring and mapping the use of the past}

\section{A. Citation, precedent, and quantitative approaches}

Citation analysis in the law has a long history, with the first studies dating back to the mid Twentieth Century. In a visionary law review article published in 1953, Merryman acknowledged the key problem of the discipline: the risk of attributing meaning to an activity that may have been carried out unreflectively and almost carelessly. ${ }^{10}$ Yet, he also argued that, citations being so widespread in the law, a rationalization of the citing effort was likely to be worthwhile. ${ }^{11}$

The field was later resurrected by law and economics scholars. ${ }^{12}$ They, too, rejected easy criticism connected to the potentially low signal-to-noise ratio, ${ }^{13}$ and relied on the same assumptions that Merryman spelled out: '[p]resumably a citation means something to the person citing, and presumably he anticipates that it will have some meaning to a reader'. ${ }^{14}$ This conclusion flows with relative ease from the fact that a citation, nonchalant as it may be, is rarely costless—not just because finding the correct one may be time-consuming, but also due to the potential for criticism that a poorly chosen authority might yield. ${ }^{15}$

As Landes and Posner acknowledged in their pioneering work, there is no going around the fact that 'a case citation is not the same thing as a precedent': ${ }^{16}$ something could be cited for the purposes of distinguishing it, overruling it, or otherwise distancing from it. Thus, analyses carried out through citation-mining may be over-inclusive, and ultimately not accurate enough to draw meaningful conclusions. However, is that, while although citations may only serve as an 'imperfect proxy', ${ }^{17}$ their very presence, as Fowler and Jeon later observed, may amount to a 'latent judgment' on the cited case, researched and chosen among many and deemed important to resolve the legal issue at hand. ${ }^{18}$ Further, a citation to a case is testament to their authority, which is restated, rather than undermined, even when it 'may have to be deflected or destroyed in order to enable the desired outcome of the current case'. ${ }^{19}$ Perhaps more crucially, misgivings as to the imperfection of this proxy must be carefully weighed with its potential: citations allow to measure the scope and extent of reliance on specific types of authority to a level of precision and with a degree of efficiency that simply cannot be matched by other techniques. Accordingly, it also allows for more ambitious macrolevel studies that take into account the evolution of case law in the aggregate.

\section{B. The shift to network analysis: The Web of Law}

The subtitle chosen by Merryman for his 1954 landmark study was What the California Supreme Court Cited in 1950.20 The implication was that the number, frequency, and identity of the authorities cited could be, in itself, illuminating. Six decades later, it is arguably possible to adopt a more holistic approach—one allowing

\footnotetext{
${ }^{10}$ John Henry Merryman, 'The Authority of Authority: What the California Supreme Court Cited in 1950' (1953) 6 Stanford Law Review 613

11 ibid.

12 William M Landes and Richard A Posner, 'Legal Precedent: A Theoretical and Empirical Analysis' (1976) 19 Journal of Law \& Economics 249.

${ }^{13}$ RA Posner, 'An Economic Analysis of the Use of Citations in the Law' (2000) 2 American Law and Economics Review 381, 387.

${ }^{14}$ Merryman (n 10) 613.

${ }^{15}$ Posner, 'An Economic Analysis of the Use of Citations in the Law' (n 13) 383.

${ }^{16}$ Landes and Posner (n 12) 251.

17 Richard A Posner, Cardozo: A Study in Reputation (University of Chicago Press 1993) 71; Joost Paulwelyn, 'Minority Rules: Precedent and Participation before the WTO Appellate Body' in Joanna Jemielniak (ed), Establishing Judicial Authority in International Economic Law (Cambridge University Press 2016) See also, employing the same expression.

18 James H Fowler and Sangick Jeon, 'The Authority of Supreme Court Precedent' (2008) 30 Social networks 16.

${ }^{19}$ Posner, 'An Economic Analysis of the Use of Citations in the Law' (n 13) 385.

${ }^{20}$ Merryman (n 10).
} 
us to make the 'wilderness of single instances' 21 less unwieldy and, in other, more prosaic words, not to miss the forest for the trees. This is, it is submitted, may be accomplished by employing network analysis.

\section{A primer on network, theory}

Network theory may be defined as a subset of graph theory concerned with the study of networks. Traditionally, the origins of this discipline are associated to Euler's quest to solve the Königsberg Bridge Problem - how to walk around the city crossing each of its bridges once, and only once. ${ }^{22}$ Euler employed graph theory to determine that one such path was impossible, thereby framing complex topological problems in rigorous mathematical terms and laying the foundations for graph and network theory, ${ }^{23}$ and legend has it that the good townspeople eventually gave up their effort to prove him wrong and built a new bridge. ${ }^{24}$ This example provides an opportunity to offer a simple definition: a network is a collection of items (nodes, or vertices) and their connections (edges, or links).

Despite the use of the word 'social', networks are everywhere: SNA is the study of structure of the relationships between entities, as well as the patterns and implications of these relationships. Thus, SNA may be employed to understand the relationships between discrete entities that do not have volition of their own, ${ }^{25}$ such as 'departments within a corporation, public service agencies in a city, or nation-states in the world system', ${ }^{26}$ but even discrete sections of a literary text, ${ }^{27}$ citations between scholarly works, ${ }^{28}$ and —of course-judicial decisions. In other words, SNA deals with relational data.

With the advent of the 'century of complexity', ${ }^{29}$ a veritable turn to networks has taken place in all disciplines and sciences. ${ }^{30}$ With an endless potential for evolution in size and tendency towards random complexity, ${ }^{31}$ the Internet has become the most studied network and an ideal testing ground. Most notably, it was by empirically mapping it that Barabási and Albert concluded that actual networks rarely share the characteristics associated with the so-called 'random' networks studied by mathematicians, but rather followed a power law, rather than a bell-shaped, distribution, that is to say, only a small percentage of the nodes (the web pages) were linked to (and, most importantly, by) others, whereas the majority had few or no such links. ${ }^{32}$

\footnotetext{
21 Tennyson's Aymer's Field.

22 See Euler's own memoir, reprinted and translated in Leonhard Euler, 'LEONHARD EULER AND THE KOENIGSBERG BRIDGES' (1953) 189 Scientific American 66.

${ }^{23}$ Ernesto Estrada, Philip A Knight and Philip Knight, A First Course in Network Theory (Oxford University Press 2015) 6-7; AlbertLászló Barabási, Network Science (Cambridge University Press 2016) 44.

${ }^{24}$ Albert-laszlo Barabasi and Jennifer Frangos, Linked: The New Science Of Networks Science Of Networks (Basic Books 2002$) 41$.

25 This accords with modern sociological theory. Consider Latour's (writing under the name 'Jim Johnson') landmark take on the issue Bruno Latour, 'Mixing Humans and Nonhumans Together: The Sociology of a Door-Closer' (1988) 35 Social Problems 298. ${ }^{26}$ Stanley Wasserman and Katherine Faust, Social Network. Analysis: Methods and Applications (Cambridge University Press 1994$) 17$.

${ }^{27}$ Franco Moretti, Graphs, Maps, Trees: Abstract Models for a Literary History (Verso 2005); Franco Moretti, Distant Reading (Verso Books 2013).

${ }^{28}$ Nees Jan van Eck and Ludo Waltman, 'Visualizing Bibliometric Networks', Measuring Scholarly Impact (Springer, Cham 2014) <https://link.springer.com/chapter/10.1007/978-3-319-10377-8_13> accessed 27 April 2018.

${ }^{29}$ Stephen Hawking, 'WHAT IS COMPLEXITY?'

30 Albert-László Barabási, ‘The Network Takeover’ (Nature Physics, 22 December 2011$)$ <https://www.nature.com/articles/nphys2188> accessed 9 August 2018.

31 Albert-laszlo Barabasi, 'Science of Networks from Society to the Web’ in János Kristóf Nyíri (ed), A Sense of Place: The Global and the Local in Mobile Communication (Passagen 2005) 415.

32 A Barab\&aacute;si, 'Emergence of Scaling in Random Networks' (1999) 286 Science 509; Albert-László Barabási and Eric Bonabeau, 'Scale-Free Networks' (2003) 288 Scientific american 60, 53.
} 
They termed this type of network 'scale-free', as 'there [was] no single node which we could pick out and claim to be characteristic of all the nodes'. ${ }^{3}$ This was so, the theory goes, because the World Wide Web was not created from the start with a roll of the dice. The number of nodes is not predefined-rather, it is continuously increasing - and the likelihood of a node acquiring additional connections not left to fate. Instead, it was a function of the original number of connections of that node.

This effect has been called many names: cumulative advantage, ${ }^{34}$ Matthew effect-another lesson from the parable of the talents_, ${ }^{35}$ and 'rich-get-richer' effect. More recently, the term 'preferential attachment' introduced by Barabási and Albert, is preferred. ${ }^{36}$ This assortment of designations, however, is no accident: on the contrary, it follows from the fact that these patterns have, for a long time, been known to occur naturally in many fields, if only anecdotally: one may mention De Solla Price observations on very well cited scientific papers, ${ }^{37}$ or the general trend whereby already bankable Hollywood stars become progressively more bankable, and also tend to have shared credits with other bankable talent. ${ }^{38}$

\section{Network analysis and the law}

The fact that a number of networks of this kind may share common characteristics suggests that the judicial output of a court of law could be studied in a similar fashion. As Thomas Smith perceptively put it, the legal field presents 'one of the largest, most accessible, and best documented human-created networks in existence-the centuries-old network of cases and other legal authorities where lawyers discover the law on any given topic'. ${ }^{39}$ Even with no knowledge of what network is, many of the conclusions discussed above may resonate with observers of the work of a court. Constant accretion and landmark precedents do not surprise us conceptually.

This approach has pioneered by Fowler and Jeon's work on the United States Supreme Court. In a series of articles, they tested several hypotheses relating to the Court's use of precedent, the evolution of the doctrine of stare decisis, and other important elements regarding the salience and importance of certain cases. ${ }^{40}$ Other studies have since adopted similar methodologies, contributing to the progressive advancement of the application of network analysis to legal citations. Though these methodologies have initially been employed for the study of common law—and, chiefly, North American—jurisdictions, they have more recently been deployed for the investigation of civil law jurisdictions, ${ }^{41}$ as well as the jurisprudence of international courts and tribunals, though with a deeper focus on regional courts, ${ }^{42}$ or

\footnotetext{
${ }_{33}$ Barabasi and Frangos (n 24) 70; The concept of scale thus differs from that suggested by Müller-Mall. See Legal Spaces: Towards a Topological Thinking of Law (Springer Science \& Business Media 2013).

34 Derek de Solla Price, 'A General Theory of Bibliometric and Other Cumulative Advantage Processes' (1976) 27 Journal of the American society for Information science 292.

35 'For unto every one that hath shall be given, and he shall have abundance': Matthew 25:14-30. See also Robert K Merton, 'The Matthew Effect in Science: The Reward and Communication Systems of Science Are Considered' (1968) 159 Science 56; Robert K Merton, 'The Matthew Effect in Science, II: Cumulative Advantage and the Symbolism of Intellectual Property' (1988) 79 isis 606.

${ }^{36}$ Barabási and Bonabeau (n 32) 55; Barabási (n 23) 168.

${ }_{37}$ Derek John de Solla Price, Little Science, Big Science-- and Beyond (Columbia University Press 1963); Price (n 34); Note, however, that the claim has been made that scientific citation networks might not be scale-free (even if they do follow a power law). See Michael Golosovsky, 'Power-Law Citation Distributions Are Not Scale-Free' (2017) 96 Physical Review E $<$ http://arxiv.org/abs/1708.01859> accessed 10 December 2018.

38 Barabasi and Frangos (n 24) 84.

${ }^{39}$ Smith (n 9) 310.

${ }^{40}$ Fowler and Jeon (n 18).

${ }^{41}$ Marc van Opijnen, 'Citation Analysis and Beyond: In Search of Indicators Measuring Case Law Importance.', JURIX (2012).

${ }^{42}$ Erik Voeten, 'Borrowing and Nonborrowing Among International Courts' (2010) 39 Journal of Legal Studies 547; Yonatan Lupu and Erik Voeten, 'Precedent in International Courts: A Network Analysis of Case Citations by the European Court of Human Rights' (2012) 42 British Journal of Political Science 413; Mattias Derlén and Johan Lindholm, 'Goodbye van Gend En Loos, Hello
} 
specific and narrow research questions in mind. ${ }^{43}$ Experiments in conventional citation analysis of international courts and tribunals have also been conducted for international courts, though with some significant delay compared to national jurisdictions. ${ }^{44}$

\section{The approach taken in this analysis}

This is a computational analysis of the citation patterns of international adjudicators. It mainly comprises citation data from the International Court of Justice (ICJ), the Appellate Body of the World Trade Organization (AB), as well as Investment Arbitration tribunals. For comparison purposes, it also refers to the citation practices of the Grand Chamber of the European Court of Human Rights (ECHR), the InterAmerican Court of Human Rights (IACHR, panels constituted under the auspices of the Court of Arbitration for Sport (CAS), the Iran-United States Claims Tribunal (IUSCT), and the World Bank Administrative Tribunal (WBAT), and builds on a dataset of over 200,000 citations and paragraphs containing them automatically extracted from all of their decisions. For macro-comparison purposes, it also refers to the citation network of the United States Supreme Court, which has been the object of several large-scale studies and serves as a general example of precedent-driven court. For reasons of consistency between different adjudicators and space, the analysis carried out in this paper generally excludes 'external precedents'.

Citations, it bears restating, are a proxy. They cannot capture all the complexity inherent in argumentative use of authoritative legal materials, and come with a risk of false positives. Accordingly, findings must be considered critically, and, before embarking in the discussion of this comprehensive charting of the citation networks, it is fitting to remind the reader that, as Alfred Korzybski put it, 'the map is not the territory': rather, its utility lies in its sensible resemblance to it. ${ }^{45}$

\footnotetext{
Bosman? Using Network Analysis to Measure the Importance of Individual CJEU Judgments' (2014) 20 European Law Journal 667; Urska Sadl and Ioannis Panagis, 'The Force of EU Case Law: An Empirical Study of Precedential Constraint' (Social Science Research Network 2016) SSRN Scholarly Paper ID 2787119 <https://papers.ssrn.com/abstract=2787119> accessed 24 March 2018; Nicola Lettieri and others, 'Correction to: A Computational Approach for the Experimental Study of EU Case Law: Analysis and Implementation' (2017) 7 Social Network Analysis and Mining 58; Mattias Derlén and Johan Lindholm, 'Is It Good Law? Network Analysis and the CJEU's Internal Market Jurisprudence' (2017) 20 Journal of International Economic Law 257; Wolfgang Alschner and Damien Charlotin, 'The Growing Complexity of the International Court of Justice's Self-Citation Network: Institutional Achievement or Access-to-Justice Concern?' (Social Science Research Network 2016) SSRN Scholarly Paper ID $2832148<$ https://papers.ssrn.com/abstract=2832148> accessed 27 February 2017.

${ }^{43}$ Krzysztof J Pelc, 'The Politics of Precedent in International Law: A Social Network Application' (2014) 108 American Political Science Review 547; Damien Charlotin, 'The Place of Investment Awards and WTO Decisions in International Law: A Citation Analysis' (2017) 20 Journal of International Economic Law 279; Niccolo Ridi, 'Approaches to External Precedent: Invocation of International Decisions in Investment Arbitration and WTO Dispute Settlement', Adjudicating International Trade and Investment Disputes: Between Isolation and Interaction (Cambridge University Press 2018).

44 Tom Ginsburg, 'Bounded Discretion in International Judicial Lawmaking' (2004) 45 Virginia Journal of International Law 631 (counting the number of citations in the jurisprudence of the ICJ); Christopher S Gibson and Christopher R Drahozal, 'Iran-United States Claims Tribunal Precedent in Investor-State Arbitration' (2006) 23 Journal of International Arbitration 521; Jeffery P\&\#46 Commission, 'Precedent in Investment Treaty Arbitration\&\#8212; A Citation Analysis of a Developing Jurisprudence' (2007) 24 Journal of International Arbitration 129.

45 Alfred Korzybski, Science and Sanity: An Introduction to Non-Aristotelian Systems and General Semantics (Institute of GS 1958$) 58$. Borges's 'Del rigor en la ciencia', originally in Historia universal de la infamia, also comes to mind. See Borges, Dreamtigers (1985) 90 ('[T]he Cartographers Guilds struck a Map of the Empire whose size was that of the Empire'); See 'On the Impossibility of Drawing a Map of the Empire on a Scale of 1 to 1', in Eco, How to Travel with a Salmon: And Other Essays (1995) 95-97.
} 

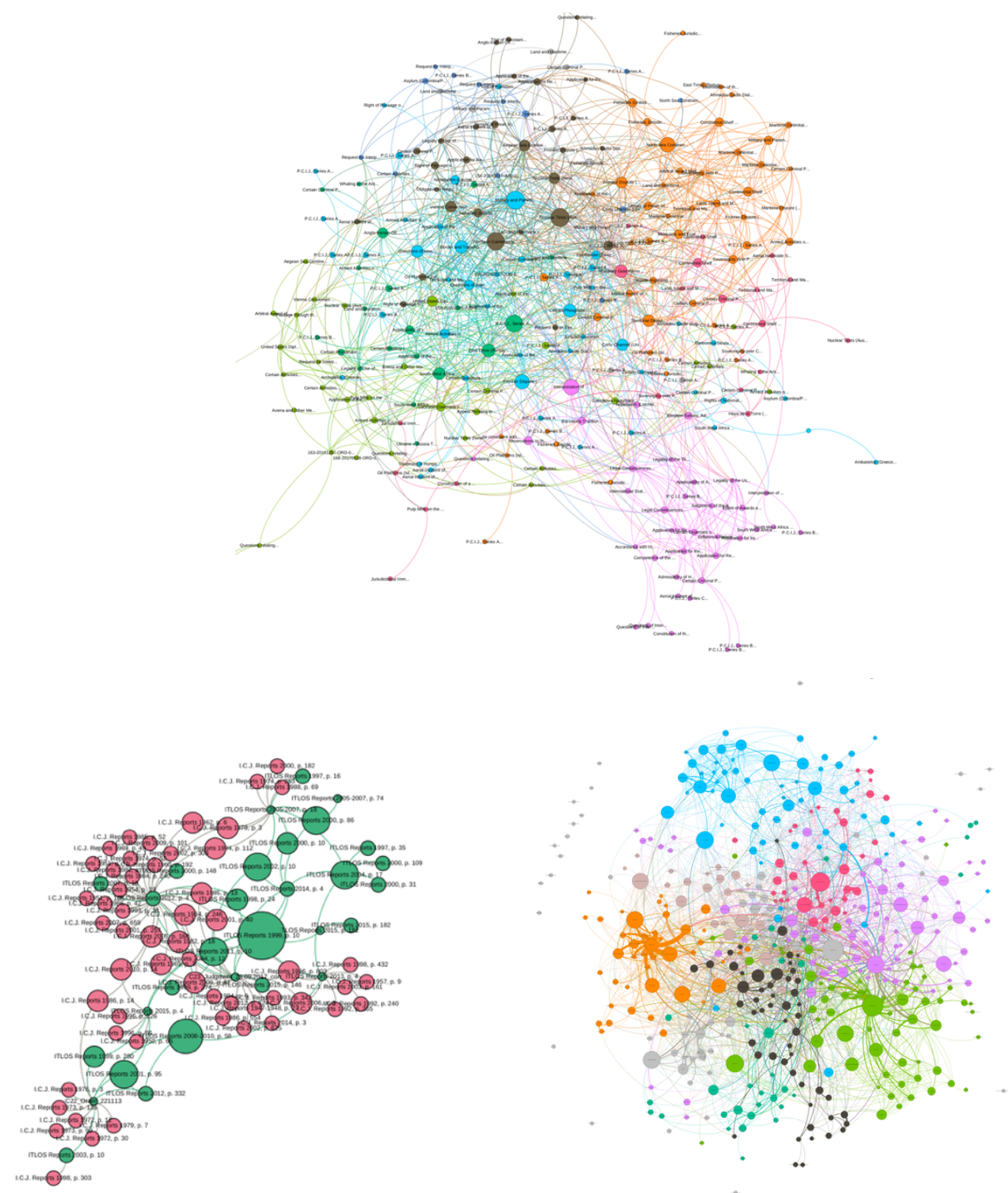

Figure 1: Above, the the core of the ICJ self-citation network (up to late 2016, partitioning follows modularity class). Below, to the right, the ITLOS citation network, inclusive of cited ICJ cases. To the right, the ECHR Grand Chamber self-citation network.
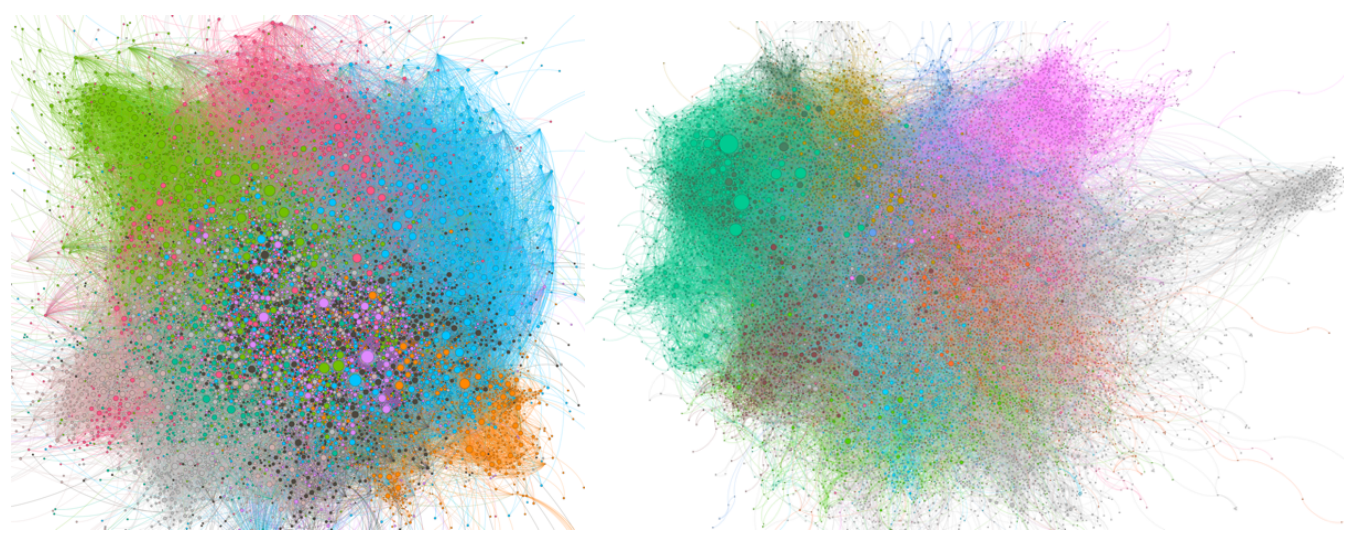

Figure 2: Comparators for the study: Cores of the full self-citation networles of the ECHR and the United States Supreme Court (up to 2002, based on data by Fowler and Jeon) 


\section{The shape and structure of the usable past}

\section{A. Preliminaries: Consistent rise, little decay}

\section{Increase in citations}

It has been acknowledged in the literature that the rise in the number of citations can be positively correlated with a growing relevance on previous decisions. In particular, Fowler and Jeon conclusively proved a strong correlation in the growth of citations and the rise, and, on the doctrinal level, the development of a norm of stare decisis. 46

Figure 3Figure 5 show the rise in citations for three of the adjudicators examined in this section, comparing the number of decisions with at least one citation issued in a given year with the number of citations made by that adjudicator to its own previous cases in the same timeframe. ${ }^{47}$ These figures demonstrate a rapid growth in the number of citations made by international adjudicators. While the passage of time is a necessary condition for these patterns to emerge - unavailable precedents cannot be cited - the three graphs show that the rise in citations has been steadily growing. Results of this kind have generally been found to correlate highly with the increase in actual reliance on previous decisions What is perhaps even more remarkable is that all the adjudicators considered in this study have started citing previous decisions quite early, in apparent contradiction of the claim not to be precedent-driven. ${ }^{48}$

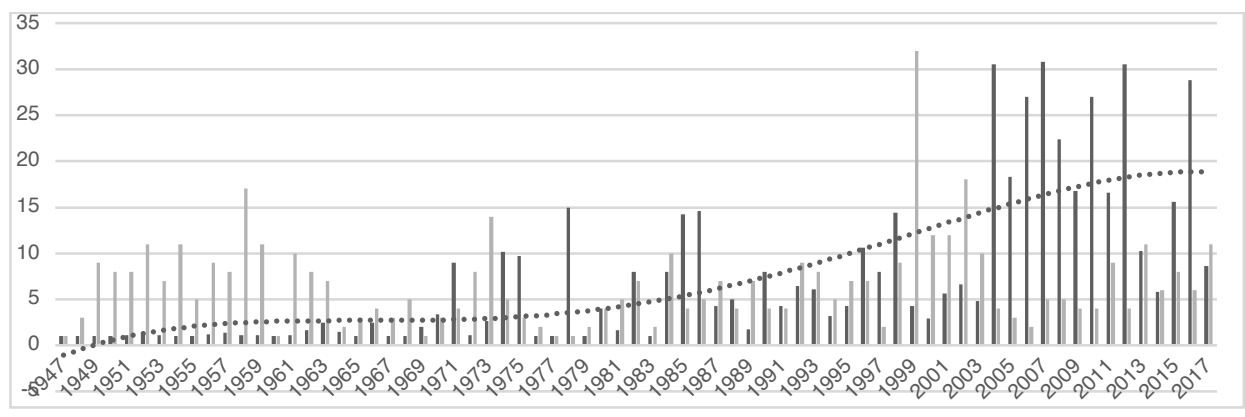

Figure 3: Number of of ICJ decisions and average number of citations per year (with polynomial trendline)

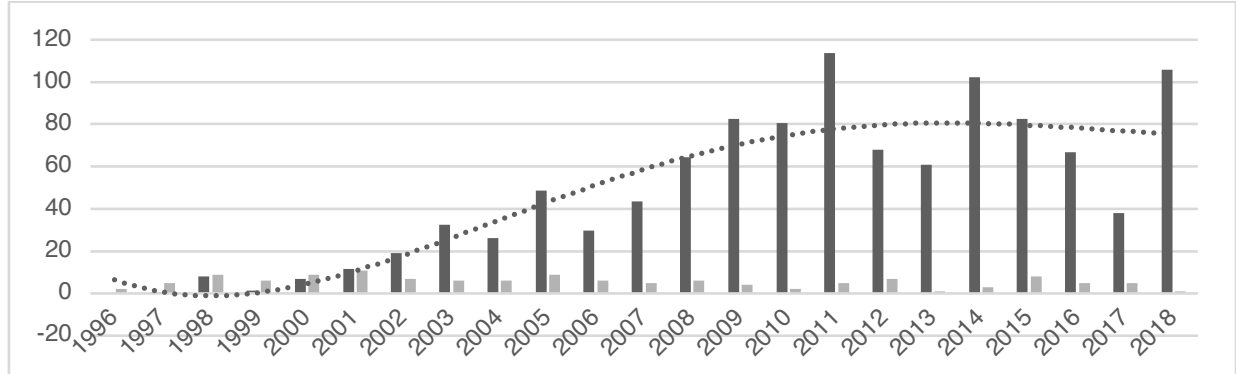

Figure 4: Number of of Appellate Body Reports and average number of self-citations per year (with polynomial trendline)

46 James H Fowler and Sangick Jeon, 'The Authority of Supreme Court Precedent' (2008) 30 Social Networks 16, 17.

47 All of the decisions for which degree $=1$ (meaning that had at least one citation, either inward or outward) were considered.

48 Mattias Derlen and Johan Lindholm, 'Peek-A-Boo, It's a Case Law System: Comparing the European Court of Justice and the United States Supreme Court from a Network Perspective Special Section: Network Analysis and Comparative Law Methods' (2017) 18 German Law Journal 647, 668-669. 


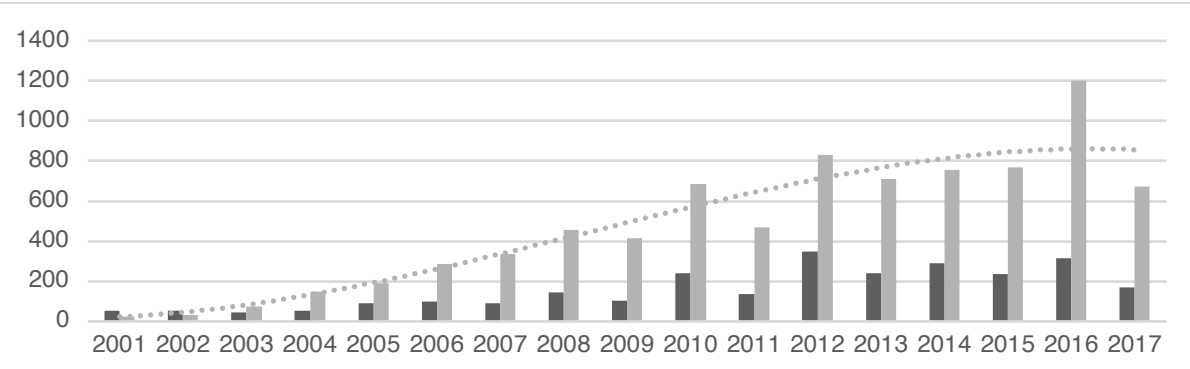

Figure 5: Number of available investment decisions making citations and number of unique citations made (2001-mid 2017).

\section{Precedent depreciation?}

As Lauterpacht put it, the value of a precedent is 'in the long run... no greater of the inherent value of the legal substance embodied in it'. ${ }^{49}$ Following this approach, it may be conjectured that the value of precedent should decrease with the passage of time. Similarly, Landes and Posner famously compared to capital stock: as societal conditions and needs change with the passage of time, the value of a precedent 'depreciates' as it requires more and more effort to be applied to the instant case, ${ }^{50}$ while better ones become availablebecause a more usable test has been articulated or a recent statute has intervened. The question thus arises: do international precedents suffer from depreciation?

To measure the extent of the phenomenon in the aggregate, the average age of a citation for any given year was then tracked. The data, plotted in Figure 6, shows that the figure has generally increased, sometimes dramatically, in the case of all permanent international courts considered in this section (ICJ, ECHR, AB, investment tribunals, IACHR). In particular, in the context of the $A B$, the average age of a precedent has increased steadily throughout the system's existence, growing to an impressive 11.53 years in 2017. In the case of the IACHR, it is possible to notice a number of significant dips-symptomatic of the tendency to innovate and all-around activism typical of the Court. ${ }^{51}$

The situation is different in the context of investment tribunals, where a very steep increase of the age of a precedent until the late 1990s is followed by a general dip in the average citation age, in turn followed by growth at a slower pace. This result may be explained by the nature of the dataset and the scarce availability of precedents - as well as publicly available decisions - in the early phases of investment jurisprudence. However, it is also symptomatic of the rise of treaty-based claims, which later grew to become the norm, and provided more appropriate precedents for comparable new cases.

Still, there is ample evidence that old—sometimes very old—precedents continue to be cited. This finding contradicts common knowledge as to how precedent is understood to operate. Indeed, besides depreciation, it is generally contended that the citation of precedents that establish or are otherwise associated with a certain proposition will eventually fade over time, as it becomes so universally accepted that a citation is redundant. ${ }^{52}$ This does not appear to be the case when international adjudicators are concerned. Rather, it is evident that old decisions keep getting cited despite new ones coming to the fore.

\footnotetext{
${ }^{49}$ H Lauterpacht, 'The So-Called Anglo-American and Continental Schools of Thought in International Law' (1931) 12 British Year Book of International Law 31, 52.

${ }^{50}$ Landes and Posner (n 12) $262 \mathrm{ff}$.

51 These finding may be compared with Fowler and Jeon's observations on the decrease in the number of outward citations during the so-called Warren Court (1953-1969), which has a reputation as a the most 'activist' of all of the US Supreme Court compositions. See Fowler and Jeon (n 46); Saul Brenner and Harold J Spaeth, Stare Indecisis: The Alteration of Precedent on the Supreme Court, 1946-1992 (Cambridge University Press 1995) 47.

52 Michael Sinclair, 'Precedent, Super-Precedent' [2006] bepress Legal Series <http://law.bepress.com/expresso/eps/1489>; Michael J Gerhardt, The Power of Precedent (Oxford University Press 2011) 177.
} 
Some rigid understanding of the relationship between precedent and citations would suggest that these patterns are indicative of stasis in the law-a conclusion that must be rejected—or, more plausibly, of a use of previous decisions that is disconnected from the idea of precedential constraint understood in inflexible terms. ${ }^{53}$

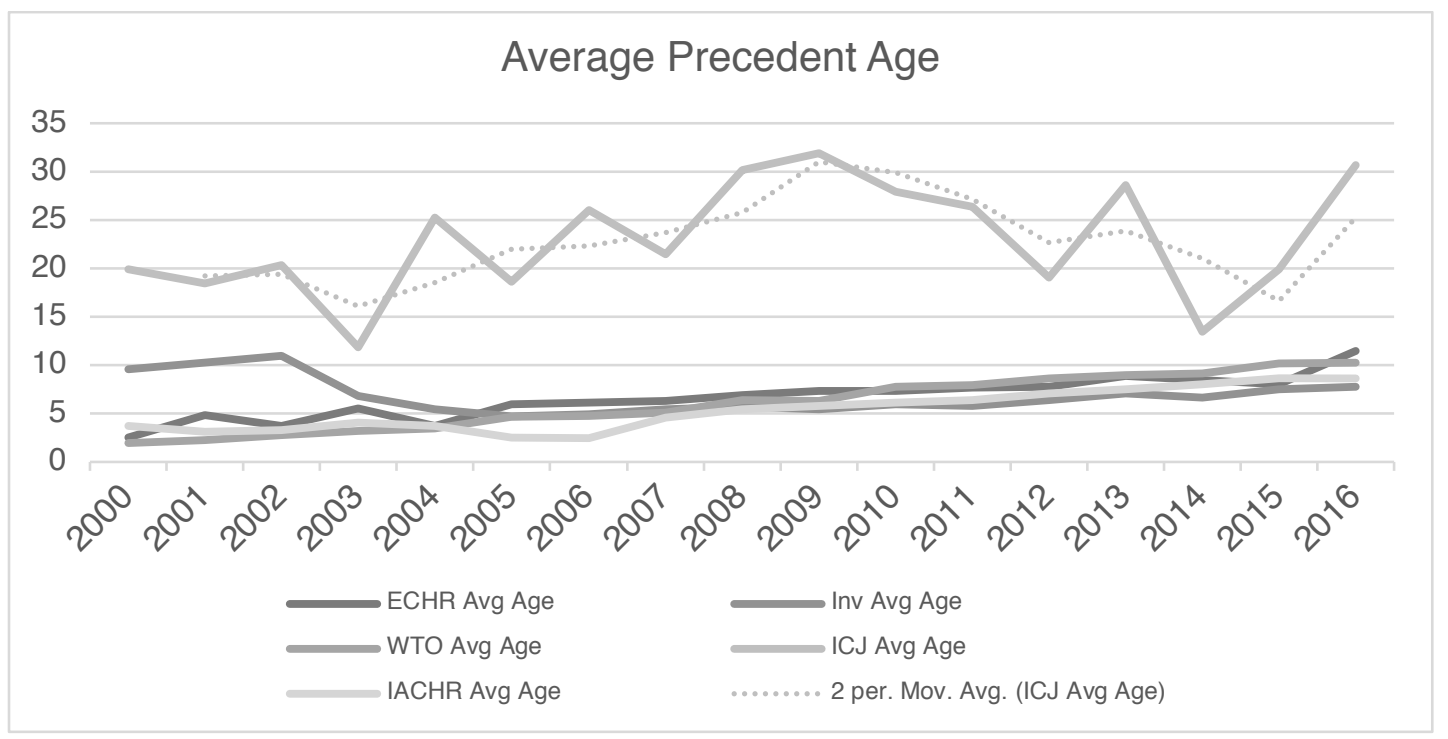

Figure 6: Average age of precedents cited by the ICJ (with moving average trendline), the ECHR, investment and WTO adjudication cases, and the IACHR, with polynomial trend line for smootbing.

\section{B. Towards greater complexity and precedent-driven dynamics: Properties of international law citation networks}

The rise of citations undoubtedly has a 'linear' dimension. However, its most significant effect may be observed in the increase it has occasioned in the complexity of the citation networks. The extent of this process may be appreciated by considering the graphical representation provided in Figure 7 and Figure 8 below, but a more accurate picture may be provided by considering the evolving mathematical properties of the network. This is accomplished by considering four different measures of network topology: density, clustering coefficient, and degree distribution.

\section{Density}

The density of citation networks may be defined as the ratio between the number of all connections to the number of possible connections in a given network with a set number of nodes. Considering these measurements, some differences between different networks start to emerge. For example, in the year 2000, the WTO AB citation network had a density of 0.304 , which only decreased to 0.245 in 2010 , and increased again to 0.263 in 2015. Conversely, the citation network of the ICJ (inclusive of citations to PCIJ cases) is far sparser: a mere 0.006 in 1960, the density value had increased threefold by 1980 (0.018), reached 0.029 by 2000 , and 0.032 by 2015 . Similarly, investment tribunals had reached a value of 0.006 by $2000,0.021$ by 2008, and 0.017 by 2017. Perhaps even more surprising are the density scores found in the investment arbitration network, which progressed steadily from a figure of 0.021 in 2000 to 0.018 in 2010 and, finally, 0.031 in 2017.

\footnotetext{
53 Landes and Posner (n 12) 274.
} 
In order to provide a workable comparator, reliance was placed on an adapted version of the data collected by Fowler and Jeon on the US Supreme Court, ${ }^{54}$ as well as a dataset comprising all of the citations made by the ECHR. Both were far sparser than the ones considered above, with densities not exceeding $0.001-$ that is to say, only $1 / 1000$ of the possible connections were made. The higher scores seen here should be considered in context: common network science wisdom stipulates that greater network sizes naturally make for lower densities. ${ }^{5}$ The US Supreme Court network and ECHR data is based on the analysis of 30,288 and 10,650 decisions respectively, whereas the AB and ICJ networks consider a corpus of a mere 134 and 695 documents. ${ }^{56}$ Yet, whether or not the lower number of precedential resources is at the root of extensive reliance on them need not matter. What the data overwhelmingly supports is the idea that reference to previous decisions is a key feature of international adjudication and that new decisions increasingly tend to be grounded in a large, and growing, variety of precedential resources.

\footnotetext{
54 The data collected by Fowler and Jeon was further refined in order to exclude all decisions with degree $<1$ (that is to say, not citing, or cited by, another decision) in order to ensure consistency with the methodology adopted thus far.

55 This point has been subject to criticism and found wanting for several real-world networks. See Jérome Kunegis, 'On the Spectral Evolution of Large Networks' <https://kola.opus.hbz-nrw.de/frontdoor/index/index/docId/581> accessed 18 January 2019.

56 Time may be added as another key variable. Fowler and Jeon's data covers the period 1754-2002: see Fowler and Jeon (n 46) 17.
} 


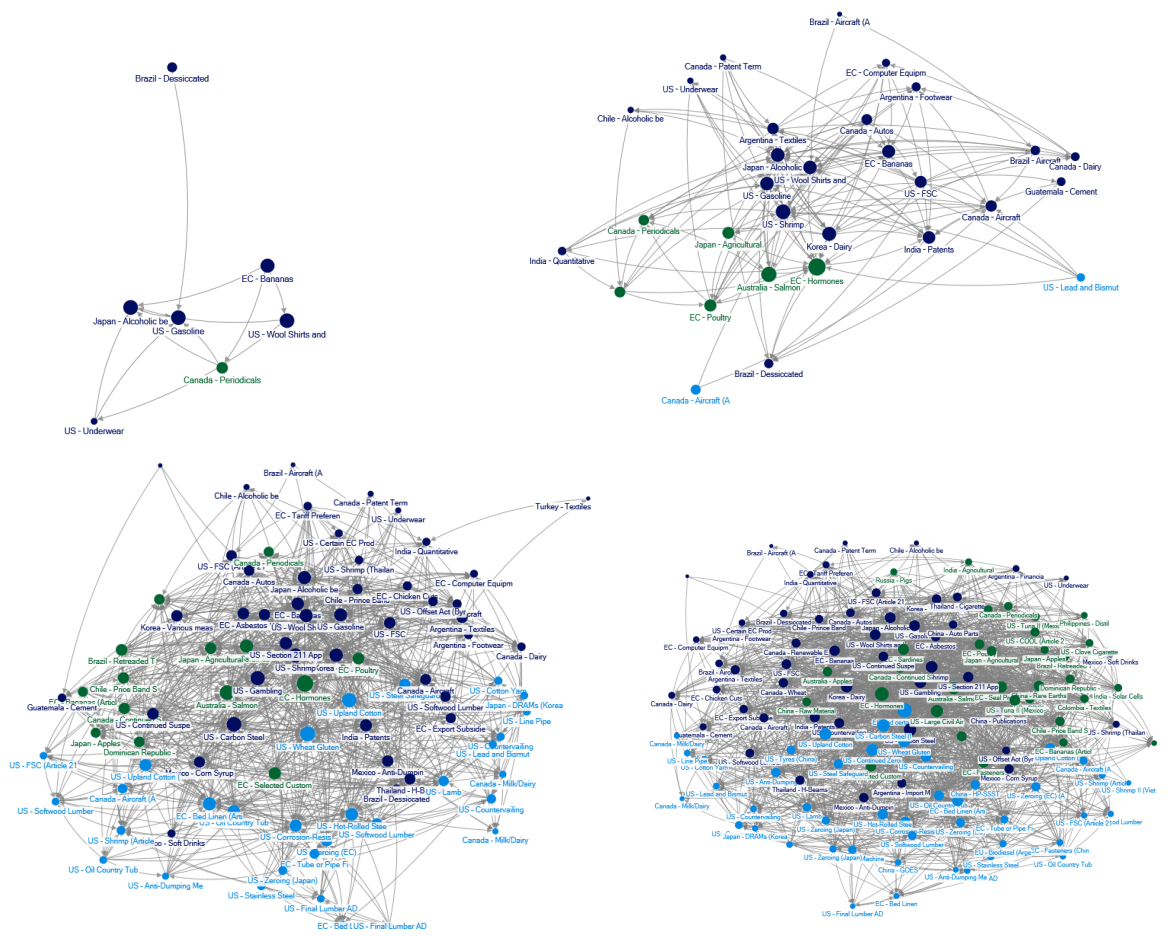

Figure 7: The evolution of the Appellate Body's citation network until 1998, 2002, 2008, and 2017. The nodes are colour-coded by modularity class

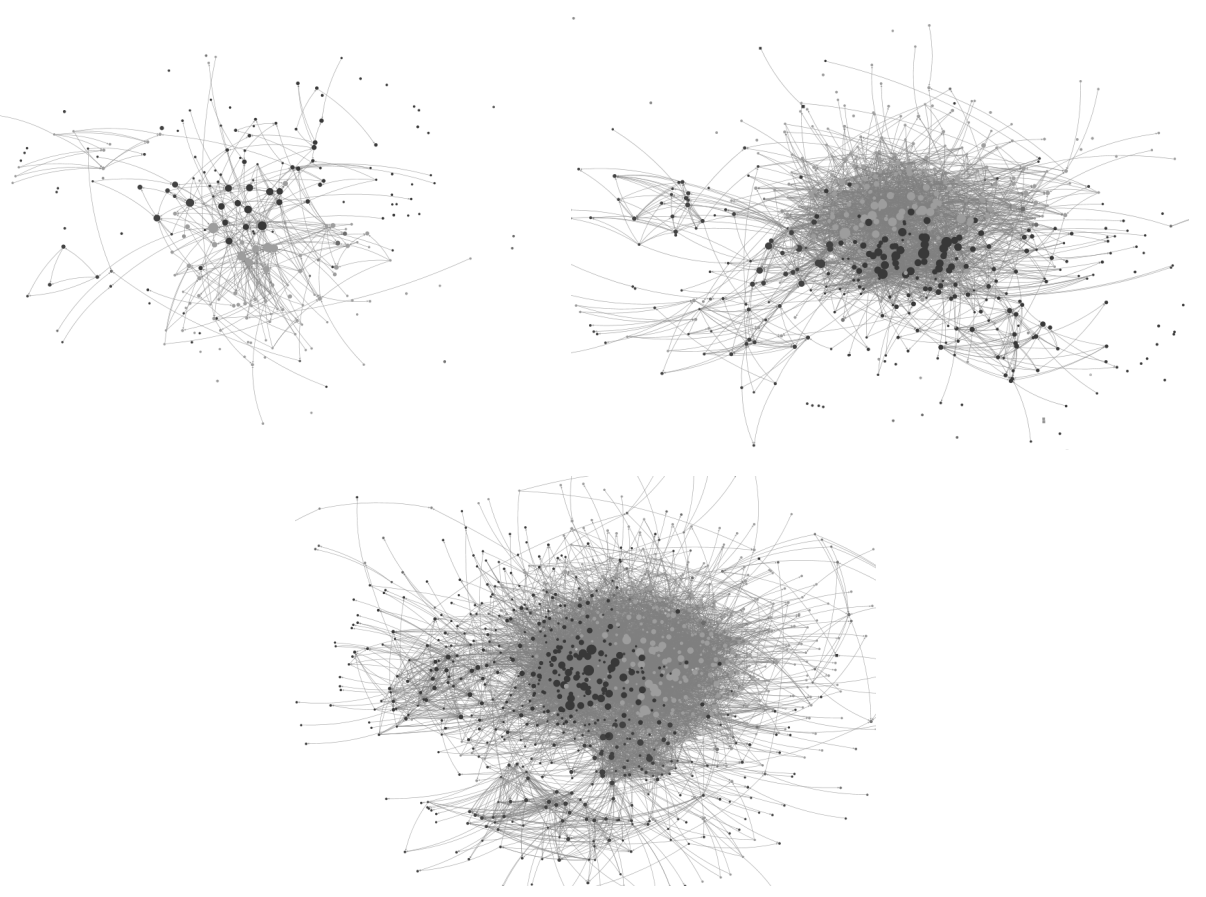

Figure 8: The evolution of the investment citation network - up to 2002, 2010, and August 2017 


\section{Clustering}

The global clustering coefficient provides information as to the connectedness of all possible triplets (or triangles) of nodes, while the local clustering coefficient uses is based on the analysis of the 'neighbourhood' of a specific node. ${ }^{57}$ In both cases, clustering coefficient provides a qualitative measure of the connectedness of a given network, chiefly serving as an indicator of a 'small-world' effect in it. ${ }^{58}$ All of the citation networks considered in this study display a relatively high global clustering coefficient. Perhaps most importantly, as shown in Figure 7, the global clustering coefficient has grown over time in all cases except the WTO AB, where it has nevertheless remained very high.

No single explanation can fully capture the complexity of this phenomenon, but two intertwined accounts may provide a workable approximation. First, the relatively high clustering coefficient provide evidence of the rapid emergence of leading cases on select matters; second, and relatedly, evidence from scientometric research suggests that figures of this type are suggestive of a tendency to 'copy' the citations already made by the cited document, thus leading to a higher degree of interconnectedness. ${ }^{59}$ In the present context, this may be symptomatic of a tendency to cite relevant decisions just because they have been, in turn, cited by a precedent, for reasons of efficiency or, more likely, in an attempt to emphasize jurisprudential coherence.
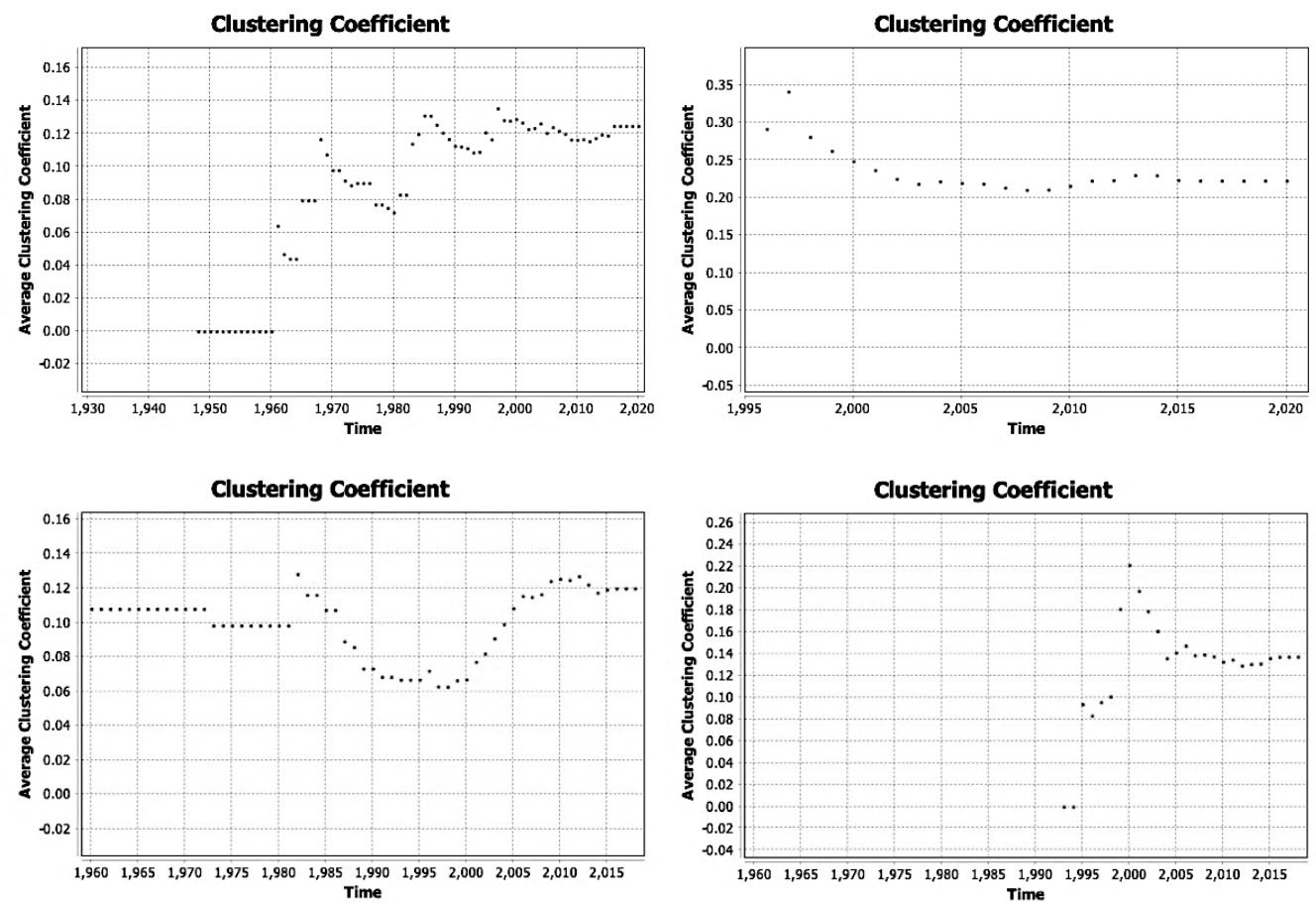

Figure 9: ICJ (top left), WTO AB (top right), investment arbitration tribunals (bottom left), and CAS tribunals (bottom right) clustering coefficients over time.

\footnotetext{
${ }^{57}$ Barabási (n 23) 63.

${ }^{58}$ Duncan J Watts and Steven H Strogatz, 'Collective Dynamics of “Small-World” Networks' (1998) 393 Nature 440 (based on the analysis of random networks). See also Jeffrey Travers and Stanley Milgram, 'The Small World Problem’ (1967) 1 Phychology Today 61.

59 MV Simkin and VP Roychowdhury, 'Read before You Cite!' [2002] arXiv:cond-mat/0212043 < http://arxiv.org/abs/condmat/0212043> accessed 17 January 2019; Lovro Šubelj, Dalibor Fiala and Marko Bajec, 'Network-Based Statistical Comparison of Citation Topology of Bibliographic Databases' (2014) $4 \quad$ Scientific $\quad$ Reports <https://www.ncbi.nlm.nih.gov/pmc/articles/PMC4178292/> accessed 17 January 2019.
} 


\section{Average degree and degree distribution}

Finally, degree distribution is defined as the probability of a certain distribution of ties for a randomly selected node in the network. ${ }^{60}$ This metric is ultimately the one that sets apart artificial, random networks from real-world, man-made networks, such as citation networks. ${ }^{61}$ As discussed above, citation networks tend to follow a power-law distribution, which is symptomatic of the 'preferential attachment' characteristics. ${ }^{62}$ All of the citation networks examined in this thesis are consistent with this account and follow long-tailed power law distributions. What is perhaps more remarkable, is that, as shown in Figure $8,{ }^{63}$ this is true for both in-degree and out-degree distributions- that is to say, the average number of incoming and outgoing citations.
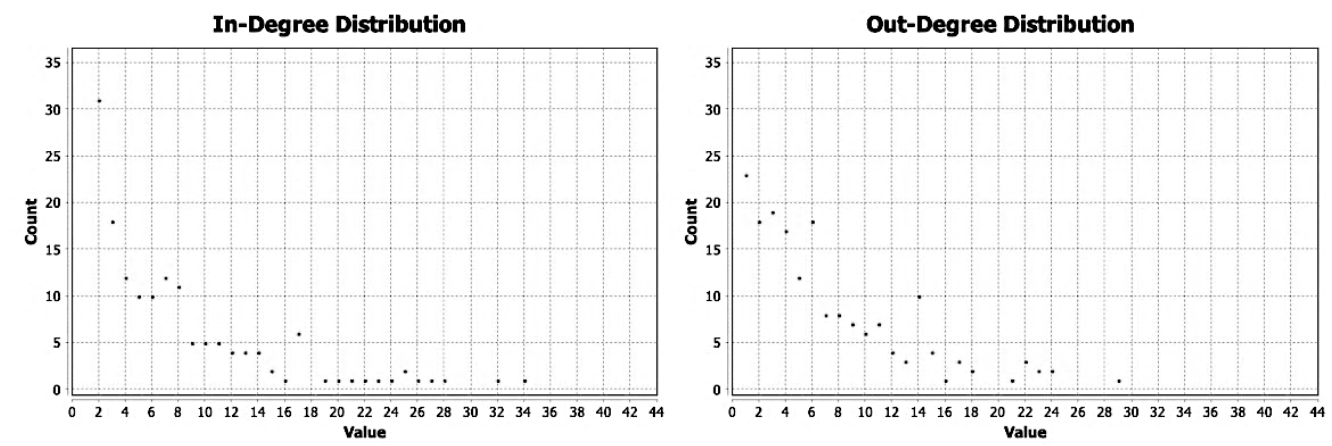

\footnotetext{
${ }^{60}$ Barabási (n 23) 49.

${ }^{61}$ Lev Muchnik and others, 'Origins of Power-Law Degree Distribution in the Heterogeneity of Human Activity in Social Networks’ (2013) 3 Scientific Reports 1783.

62 Barabási (n 23) 168.

${ }^{63}$ The power law distribution of degree makes the use of standard deviation an explanatory device unhelpful. Accordingly, graphical representation is preferable For a leading study on the problem see A Clauset, C Shalizi and M Newman, 'Power-Law Distributions in Empirical Data' (2009) 51 SIAM Review 661.
} 

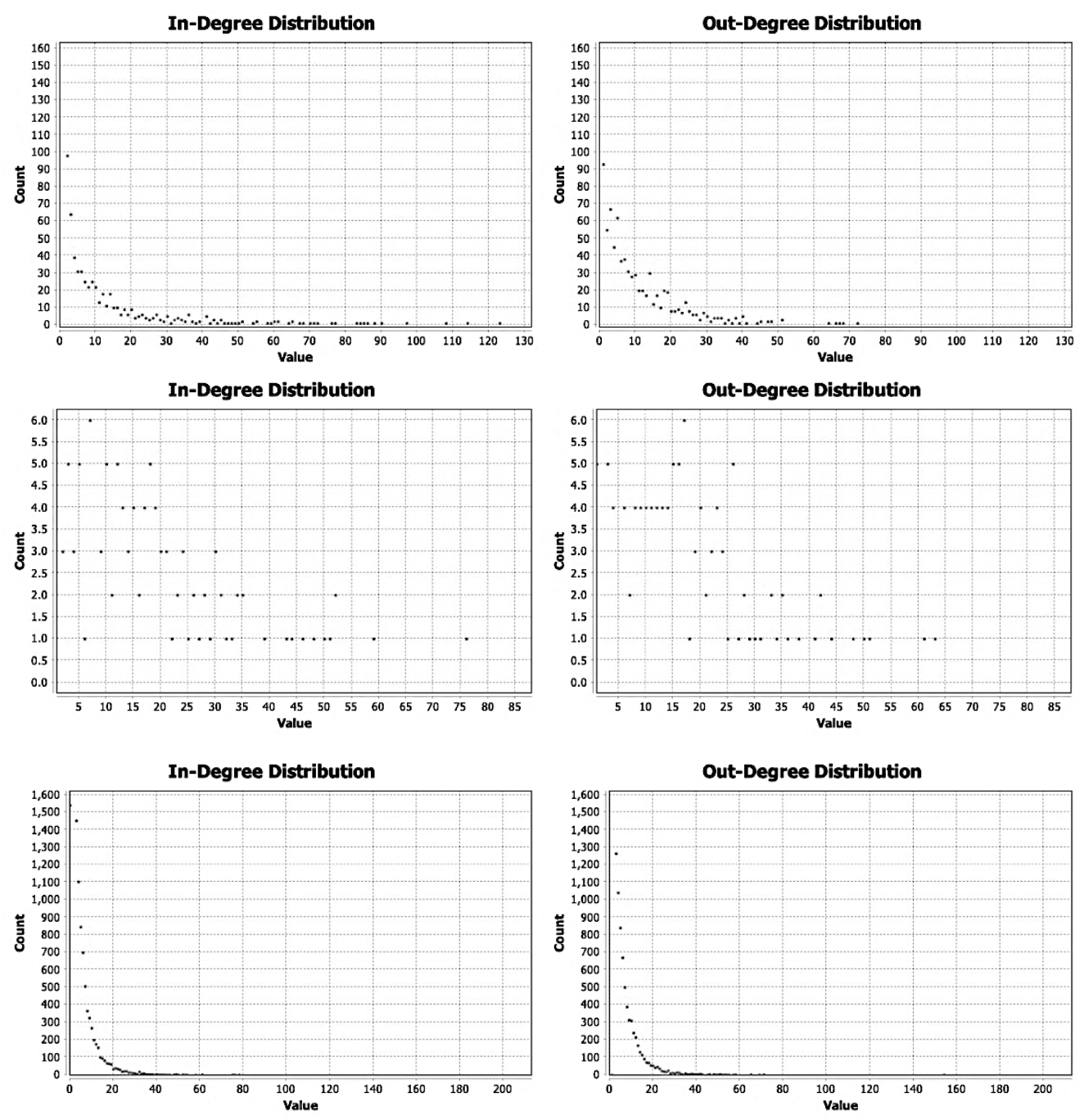

Figure 10: In-degree and out-degree distribution for the citation networks of (from top to bottom) the ICJ, investment tribunals, and the WTO AB, and US Supreme Court.

\section{An interim assessment}

The properties of these adjudicators' citation networks strongly support the contention that the use of precedent might have grown in importance. In addition, these measurements are remarkably close to those of a common law, precedent-driven court such as the US Supreme Court, further suggesting that very similar dynamics might be at play.

\section{Central cases}

It is instructive to consider which items in the network are the most 'central'- the network analysis equivalent of real-world importance. However, contrary to other areas of the law, no general database provides a ranking of decisions on the basis of importance. By way of alternative, it would be possible to consider the citations of decisions cases in casebooks and textbooks, but this methodology, too, is subject to significant limitations and is likely to reflect personal biases. ${ }^{64}$

${ }^{64}$ See Anthea Roberts, Is International Law International? (Oxford University Press 2017) 146 ff. 
A better strategy is to focus on the evaluations provided by the very adjudicators that issued these decisions: simply asking those sitting on their benches for a list, however, would be difficult, time-consuming, and likely to allow too much room for personal preferences. In the alternative, it is possible to focus on adjudicators $d o$, rather than say, and consider the evaluations of the case law as emerging directly from the citation networks.

Different network centrality measures exist. However, since they are predicated on different ideas of importance, and results may vary widely, no one method has won the approval of the scholarly community. ${ }^{65}$ For example, due to the long-tailed degree distribution of scale-free networks, a simple citation count is unhelpful. Indeed, not all connections as equally 'valuable', and secondly because they provide a highly skewed representation of the importance of specific nodes without accounting for topological questions - in other words, the position of a high-scoring node within the network.

The argument may be made that citing decisions may have some significance. A decision that cites many good authorities could serve as an authoritative collation of, or map to, information. Hence the development of link analysis algorithms. Kleinberg's Hyperlink-Induced Topic Search (HITS), chosen here, was designed with a view to understanding the relative importance of webpages - in other words, to discover 'the most "authoritative" pages in certain given topics. ${ }^{66}$ 'Hub pages', Kleinberg submitted, 'link densely to a set of thematically related authorities'. ${ }^{67}$ Accordingly, HITS assigns both 'authority' scores and 'hub' scores. Decisions will receive high 'authority' scores so long as they are cited by 'hubs' with high 'hub' score, while, 'hub' scores are determined on the basis of how many good 'authorities' they cite, and so on, recursively.68 This choice was put to the test through regression analyses and proved accurate as a predictor of citationsper-year scores (Figure 11).

\footnotetext{
65 Thom Neale, 'Citation Analysis of Canadian Case Law' (2013) 1 J. Open Access L. 1; Sadl and Panagis (n 42) (focusing on indegree and PageRank); Derlén and Lindholm, 'Is It Good Law?' (n 42); Derlen and Lindholm (n 48); Ian Carmichael and others, 'Examining the Evolution of Legal Precedent Through Citation Network Analysis' (2017) 96 NCL Rev. 227, 253.

${ }^{66}$ Jon M Kleinberg, 'Authoritative Sources in a Hyperlinked Environment', In Proceedings of the ACM-SLAM Symposium on Discrete Algorithms (Citeseer 1998) 1.

67 ibid 27.

${ }^{68}$ For additional discussion of these points, see Fowler and Jeon (n 18) 11; Neale (n 65) 14.
} 

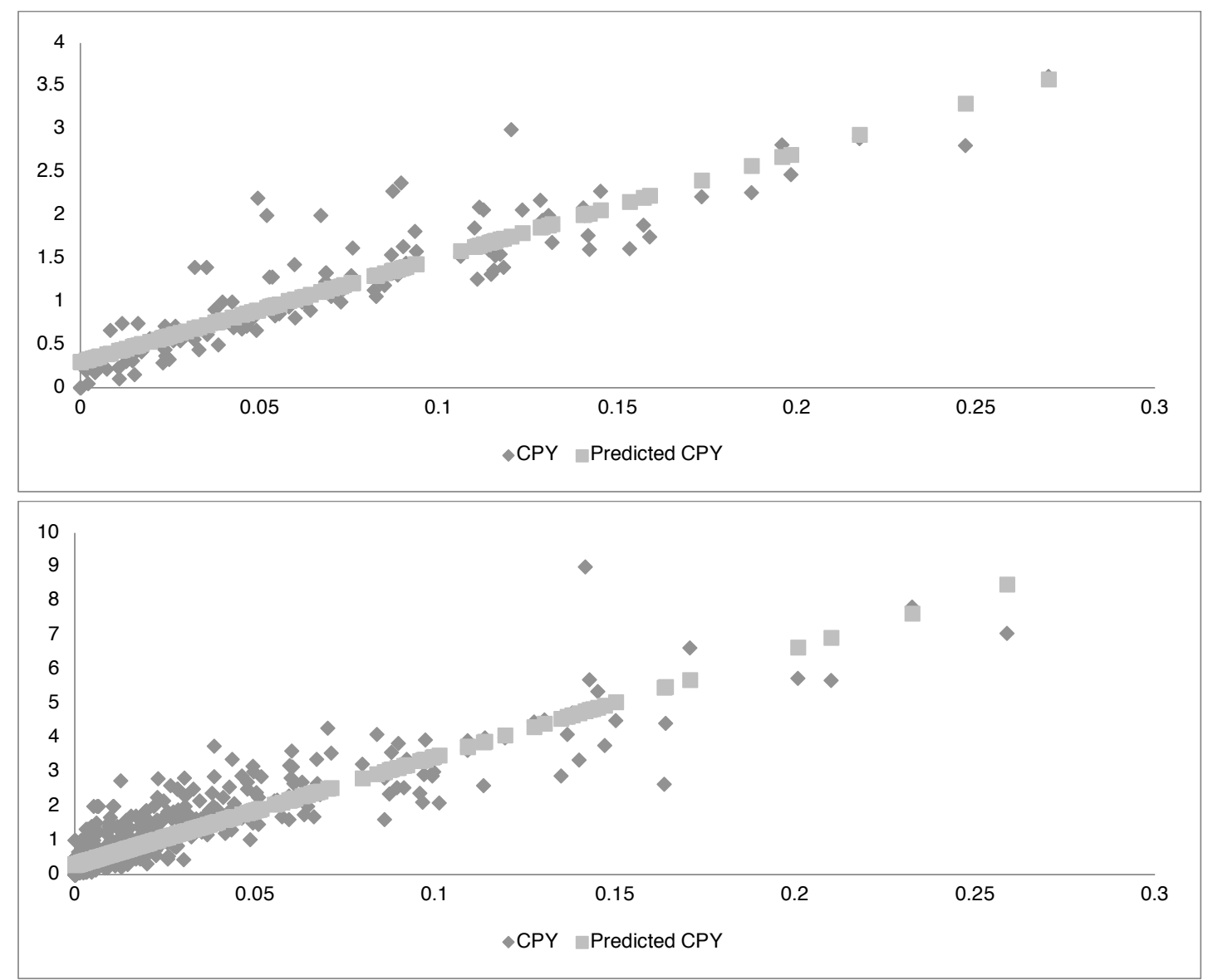

Figure 11: Regression analysis for authority scores and citations per year in the WTO AB and investment jurisprudence (confidence interval 95

Table 1: Authority scores for the 10 top-ranking decisions

\begin{tabular}{|c|c|c|c|c|c|}
\hline Decision & $\begin{array}{l}\text { Authority } \\
\text { Score }\end{array}$ & Decision & $\begin{array}{l}\text { Authority } \\
\text { Score }\end{array}$ & Decision & $\begin{array}{l}\text { Authority } \\
\text { Score }\end{array}$ \\
\hline $\begin{array}{l}\text { Nuclear Tests (Australia v. France), } \\
\text { Judg. } 20 \text { Dec. } 1974\end{array}$ & 0.33 & EC-Hormones & 0.27 & $\begin{array}{l}\text { Técnicas Medioambientales } \\
\text { Tecmed, S.A. v. United Mexican } \\
\text { States, ICSID Case No. ARB } \\
\text { (AF)/00/2, Award, } 29 \text { May } \\
2003\end{array}$ & 0.26 \\
\hline $\begin{array}{l}\text { Northern Cameroons (Cameroon v. } \\
\text { United Kingdom), Judg. } 2 \text { Dec. } 1963\end{array}$ & 0.31 & Australia-Salmon & 0.25 & $\begin{array}{l}\text { Saluka Investments B.V.v. Crech } \\
\text { Republic, UNCITRAL, Partial } \\
\text { Award, } 17 \text { March } 2006\end{array}$ & 0.23 \\
\hline $\begin{array}{l}\text { Questions of Interpretation and } \\
\text { Application of the } 1971 \text { Montreal } \\
\text { Convention arising from the Aerial } \\
\text { Incident at Lockerbie (Libyan Arab } \\
\text { Jamabiriva v. United Kingdom), } \\
\text { Preliminary Objections, Judg. } 27 \\
\text { Feb. } 1998\end{array}$ & 0.23 & US - Wheat Gluten & 0.22 & $\begin{array}{l}\text { CMS Gas Transmission Company } \\
\text { v. Republic of Argentina, ICSID } \\
\text { Case No. ARB/01/8, Award, } \\
12 \text { May } 2005\end{array}$ & 0.21 \\
\hline $\begin{array}{l}\text { Military and Paramilitary Activities in } \\
\text { and against Nicaragua (Nicaragua } v \\
\text { United States of America), Jurisdiction } \\
\text { and Admissibility, Judg. } 26 \text { Nov. } \\
1984\end{array}$ & 0.22 & US - Sbrimp & 0.20 & $\begin{array}{l}\text { Azurix Corp. v. Argentine } \\
\text { Republic, ICSID Case No. } \\
\text { ARB/01/12, Award, } 14 \text { July } \\
2006\end{array}$ & 0.20 \\
\hline
\end{tabular}




\begin{tabular}{|c|c|c|c|c|c|}
\hline $\begin{array}{l}\text { Vienna Convention on Consular } \\
\text { Relations (Paraguay v. United States of } \\
\text { America), Order } 8 \text { June } 1998\end{array}$ & 0.22 & US - Carbon Steel & 0.20 & $\begin{array}{l}\text { Compañia de Aguas del } \\
\text { Aconquija S.A. and Vivendi } \\
\text { Universal (formerly Compagnie } \\
\text { Générale des Eaux) v. Argentine } \\
\text { Republic, ICSID Case No. } \\
\text { ARB/97/3, Decision on } \\
\text { Annulment, 3 July } 2002\end{array}$ & 0.17 \\
\hline $\begin{array}{l}\text { Aegean Sea Continental Shelf (Greece v. } \\
\text { Turkey), Judg. } 19 \text { Dec. } 1978\end{array}$ & 0.21 & Korea-Dairy & 0.19 & $\begin{array}{l}\text { MTD Equity Sdn. Bbd. and } \\
\text { MTD Chile S.A. v. Republic of } \\
\text { Chile, ICSID Case No. } \\
\text { ARB } / 01 / 7 \text {, Award, } 25 \text { May } \\
2004\end{array}$ & 0.16 \\
\hline $\begin{array}{l}\text { Nuclear Tests (New Zealand v. France), } \\
\text { Judg. } 20 \text { Dec. } 1974\end{array}$ & 0.20 & US - Gasoline & 0.17 & $\begin{array}{l}\text { Asian Agricultural Products LTD } \\
\text { (AAPL) v. Republic of Sri } \\
\text { Lanka, ICSID Case No. } \\
\text { ARB } / 87 / 3 \text {, Final Award, } 27 \\
\text { June } 1990\end{array}$ & 0.16 \\
\hline $\begin{array}{l}\text { Mavrommatis, P.C.I.J., Series A, No. } \\
2\end{array}$ & 0.20 & $\begin{array}{l}\text { Japan-Agricultural } \\
\text { Products }\end{array}$ & 0.16 & $\begin{array}{l}\text { LG\&E Energy Corp., LG\&E } \\
\text { Capital Corp. and LG\&E } \\
\text { International Inc. v. Argentine } \\
\text { Republic, ICSID Case No. } \\
\text { ARB/02/1, Decision on } \\
\text { Liability, } 3 \text { October } 2006\end{array}$ & 0.15 \\
\hline $\begin{array}{l}\text { Fisheries Jurisdiction (Spain v. Canada), } \\
\text { Jurisdiction of the Court, Judg. } 4 \\
\text { Dec. } 1998\end{array}$ & 0.19 & $E C-$ Asbestos & 0.16 & $\begin{array}{l}\text { Occidental Exploration and } \\
\text { Production Company } v \text {. Republic of } \\
\text { Ecuador, LCIA Case No. } \\
\text { UN3467, Final Award, } 1 \text { July } \\
2004\end{array}$ & 0.15 \\
\hline $\begin{array}{l}\text { Interpretation of Peace Treaties with } \\
\text { Bulgaria, Hungary and Romania, First } \\
\text { Phase, Advis. Opin. } 30 \text { Mar. } 1950\end{array}$ & 0.17 & EC-Poultry & 0.15 & $\begin{array}{l}\text { SGS Société Générale de } \\
\text { Surveillance S.A. } v \text {. Republic of } \\
\text { the Pbilippines, ICSID Case No. } \\
\text { ARB/02/6, Decision on } \\
\text { Jurisdiction, } 29 \text { January } 2004\end{array}$ & 0.15 \\
\hline $\begin{array}{l}\text { North Sea Continental Shelf (Federal } \\
\text { Republic of Germany/Denmark; } \\
\text { Federal Republic of } \\
\text { Germany/Netherlands), Judg. 20 Feb. } \\
1969 \text { (Reports 1969, p. 3) }\end{array}$ & 0.16 & US - Gambling & 0.15 & $\begin{array}{l}\text { Salini Costruttori S.P.A. and } \\
\text { Italstrade S.P.A. v. Kingdom of } \\
\text { Morocco, ICSID Case No. } \\
\text { ARB/00/4, Decision on } \\
\text { Jurisdiction, } 16 \text { July } 2001\end{array}$ & 0.14 \\
\hline
\end{tabular}

Network science studies have generally found a correlation between the initial out-degree (or hub) score of a specific node and its growing importance over time. Empirical studies on precedent in common law jurisdictions have in fact found the measure - which amounts to the number of outward citations - a better predictor of the chance of future inward citations. ${ }^{69}$ The theoretical reason is that a highly citing authority is likely to store valuable information by virtue of the links to other authorities. In order to test this hypothesis, a relatively simple regression analysis was carried out to establish whether it was possible to consider the number of citations made by a decision - a time-agnostic measure-an accurate predictor of its overall importance at the time of analysis (the authority score).

The results, shown in Figure 12, show that outward citations are in fact a very poor predictor of authoritywhich, in turn, correlates strongly with the overall citations-per-year score. The finding is consistent with the tendency, described above, to cite older cases, which were also unlikely to cite as many precedents as later ones, for no other constraint than availability. It is thus entirely possible that one such relationship between outward citations and authority will arise at some point in the future.

${ }^{69}$ Ian Carmichael and others, 'Examining the Evolution of Legal Precedent Through Citation Network Analysis' (2017) 96 NCL Rev. 227, 253. 

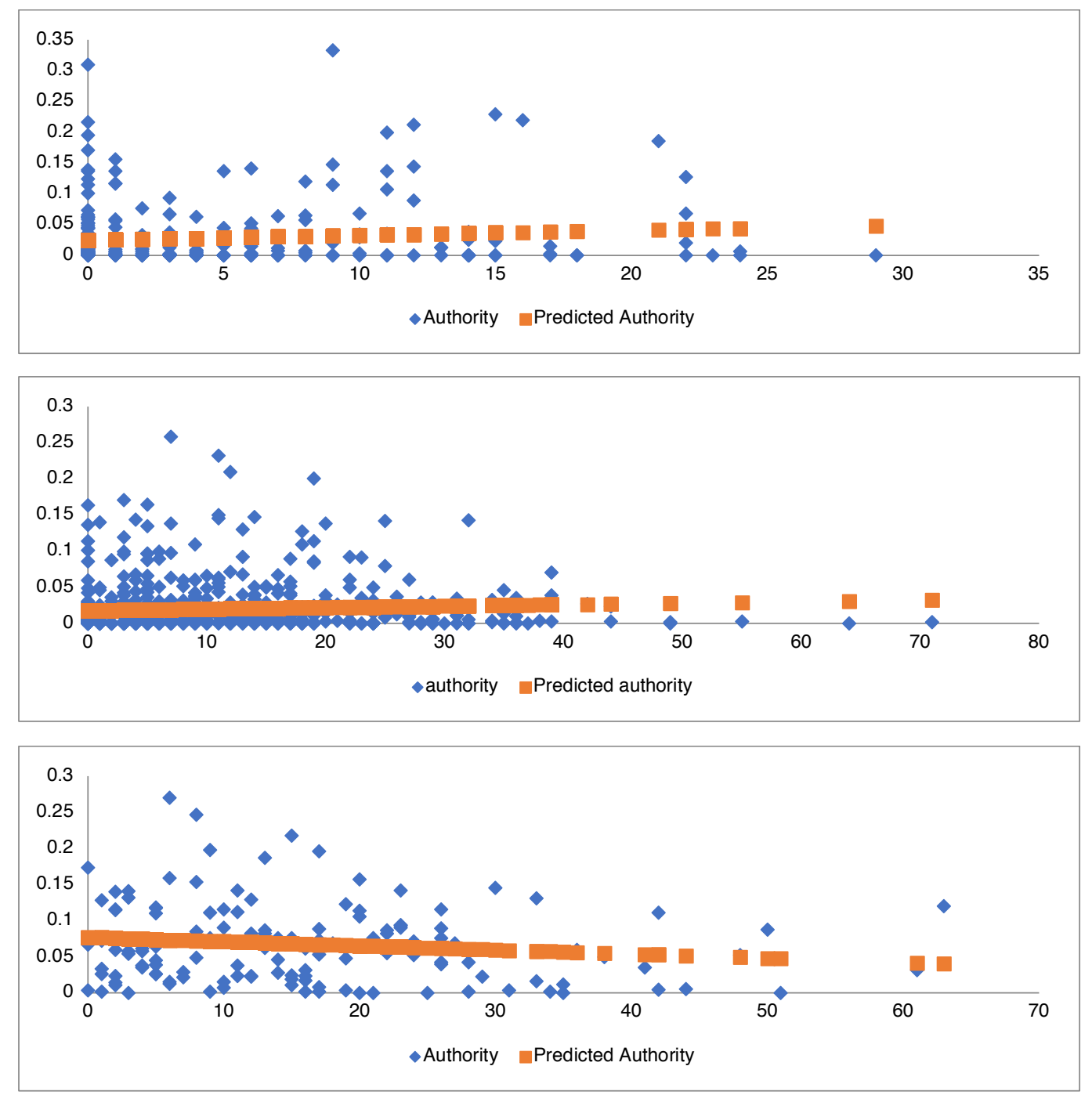

Figure 12: Regression analysis for authority and out-degree. The number of outward citations is not a good predictor for overall importance

\section{Select issues in the topology of international law citation networks}

\section{Stages and functions}

One of the most striking features of the WTO and Investment networks is that citations tend correlate strongly with the stage of the proceedings. Naturally, similar legal proceedings hinge on similar legal questions, and the same type of decisions will serve as the best repositories for relevant arguments and information. In the WTO context, for example, this phenomenon is clearly observable in the context of arbitrations under Article 21.3(c) or 22.6 DSU, which are highly specialised forms of dispute settlement. In network terms, the citation patterns occurring among these arbitrations tend to create strongly clustered and interconnected communities of case law. These decisions, however, have very few connections with the remaining body of WTO case law.

The graph below compares the stage in which a decision was pronounced with its network modularity class, a measure designed to identify nodes that are more densely connected to each other than to the rest of the network. ${ }^{70}$ As Figure 13 shows, arbitral proceedings (in green) under both articles share few connections

70 Mark EJ Newman, 'Modularity and Community Structure in Networks' (2006) 103 Proceedings of the national academy of sciences 8577,8578 , defining modularity as 'up to a multiplicative constant, the number of edges falling within groups minus the 
with the rest of the network, which is made up of panel reports (purple) and AB reports (orange). However, once a modularity measurement is applied, it is clear that the two clusters have little in common. What is more, while in both cases there is limited reliance on the work of the panels and the $A B$, arbitrations under Article 21.3(c) are somewhat even less likely to make use of it than those conducted under Article 22.6-a finding that is all the more striking when it is borne in mind that the former, and not the latter, are administered by members of the AB..$^{71}$
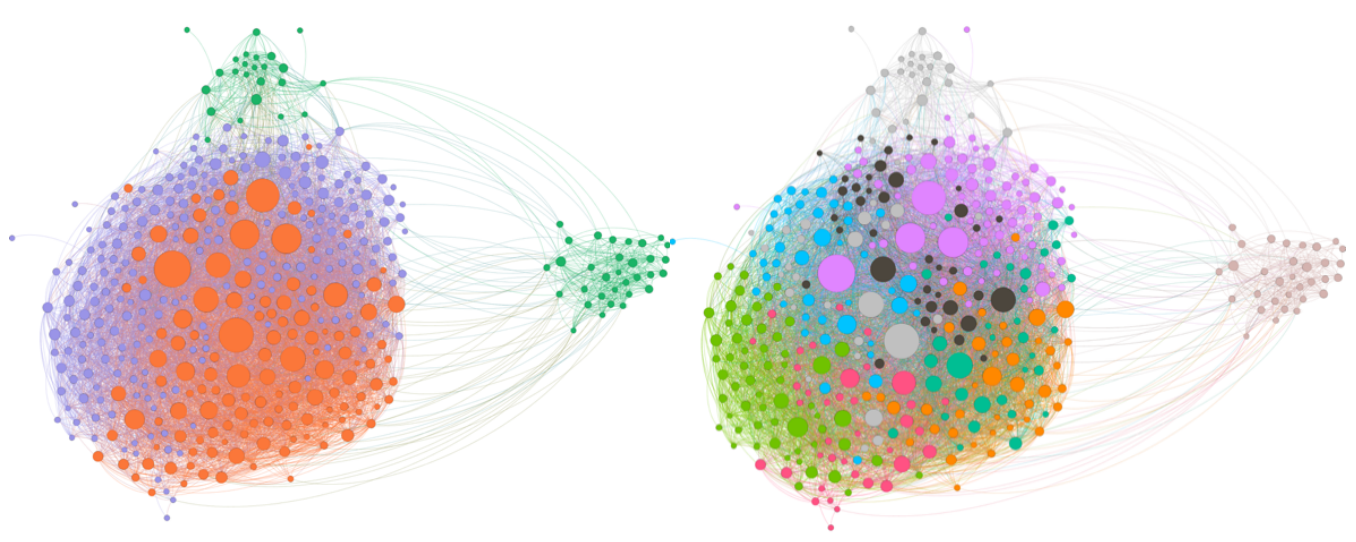

Figure 13: WTO Dispute Settlement Citation Network - Stages and modularity class

A similar approach may be fruitfully employed in the case of the investment citation network. Not surprisingly, the algorithms employed in this analysis show that significant clustering occurs along the lines of the stage of the proceedings. Accordingly, awards tend to cite awards, while decisions on provisional measures, stay of enforcement, and disqualification tend to be connected to each other far more than they are to the rest of the network. The graphs in Figure 14 compare the citation networks of all of international investment arbitration and the IACHR. Even to the naked eye, the difference in clustering is striking, with the IACHR network much more connected overall, the only outliers being some (but not all) judgments on interpretation requests. This is testament to the different approach of the Court, which tends to cumulate different procedural phases in the same judgment. This due, in part, to the different organizational model of the Court, which works in scheduled sessions. ${ }^{72}$

Decisions on annulment, tend to be relatively more connected to the main cluster, but are still rarely cited by decisions in different stages. Out of a dataset of 8104 unique citations made by investment tribunals to other investment decisions, only 282 (equalling 3.48\%) were made to decisions in the annulment phase. To further substantiate this figure, it may be added that the power law phenomenon discussed above is particularly strong in the context of citations of annulment decisions, with eight decisions in annulment proceedings making up for $71.63 \%$ of all of the citations to that phase. ${ }^{73}$ In yet another reminder of the differences between annulment and appeal, ${ }^{74}$ these patterns may be contrasted with a largely different figure

\footnotetext{
expected number in an equivalent network with edges placed at random'. See also MEJ Newman and M Girvan, 'Finding and Evaluating Community Structure in Networks' (2004) 69 Physical Review E 026113; Vincent D Blondel and others, 'Fast Unfolding of Communities in Large Networks' (2008) 2008 Journal of Statistical Mechanics: Theory and Experiment P10008.

71 \#cite

72 See Article 22 of the IACHR Statute. On the 'part-time basis' workings of the Court, see Jo M Pasqualucci, The Practice and Procedure of the Inter-American Court of Human Rights (Cambridge University Press 2013) 25.

73 These questions will be examined in greater detail in Part VI.

${ }_{74}$ Noemi Gal-Or, 'The Concept of Appeal in International Dispute Settlement' (2008) 19 European Journal of International Law 43.
} 
in the context of W'TO adjudication. In that context, in a network of 8730 ties, 3198 individual references were made by panels to Appellate Body Reports, amounting to $36.6 \%$ of the total.
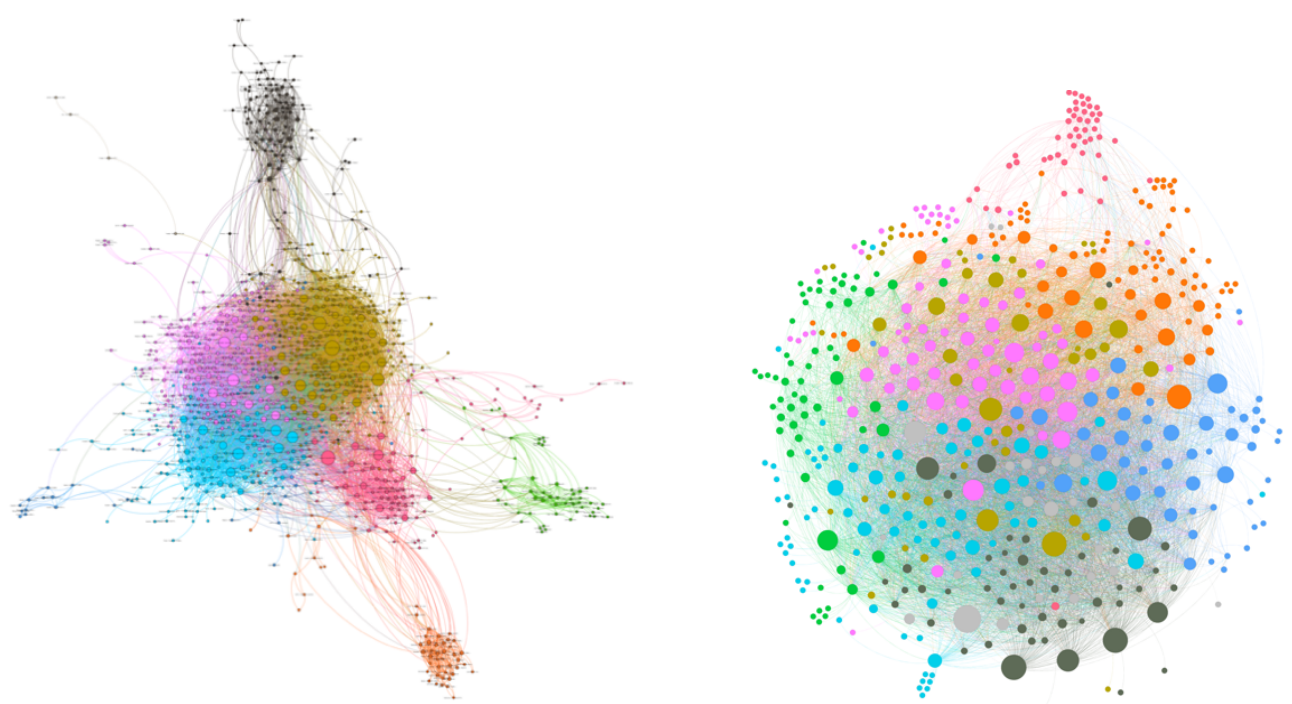

Figure 14: The investment arbitration (left) and the LACHR (right) citation networks.

A similar approach may be adopted to assess the extent to which ICJ Advisory Opinions form part of the precedential material employed by the ICJ. There is, of course abundant anecdotal evidence that ICJ advisory opinions are replete of citations to precedent. ${ }^{75}$ An examination of the ICJ citation network allows to make the further conclusion that advisory opinions are indeed more connected to each other than to the rest of the network (a conclusion that suggests the development the a law on its advisory jurisdiction), but are also, in the aggregated, far from isolated from the rest of the network.

${ }^{75}$ See, for example, Legal Consequences of the Construction of a Wall in the Occupied Palestinian Territory, Advisory Opinion, I. C. J. Reports 2004, p. 136, which has an out-degree score of 21. 

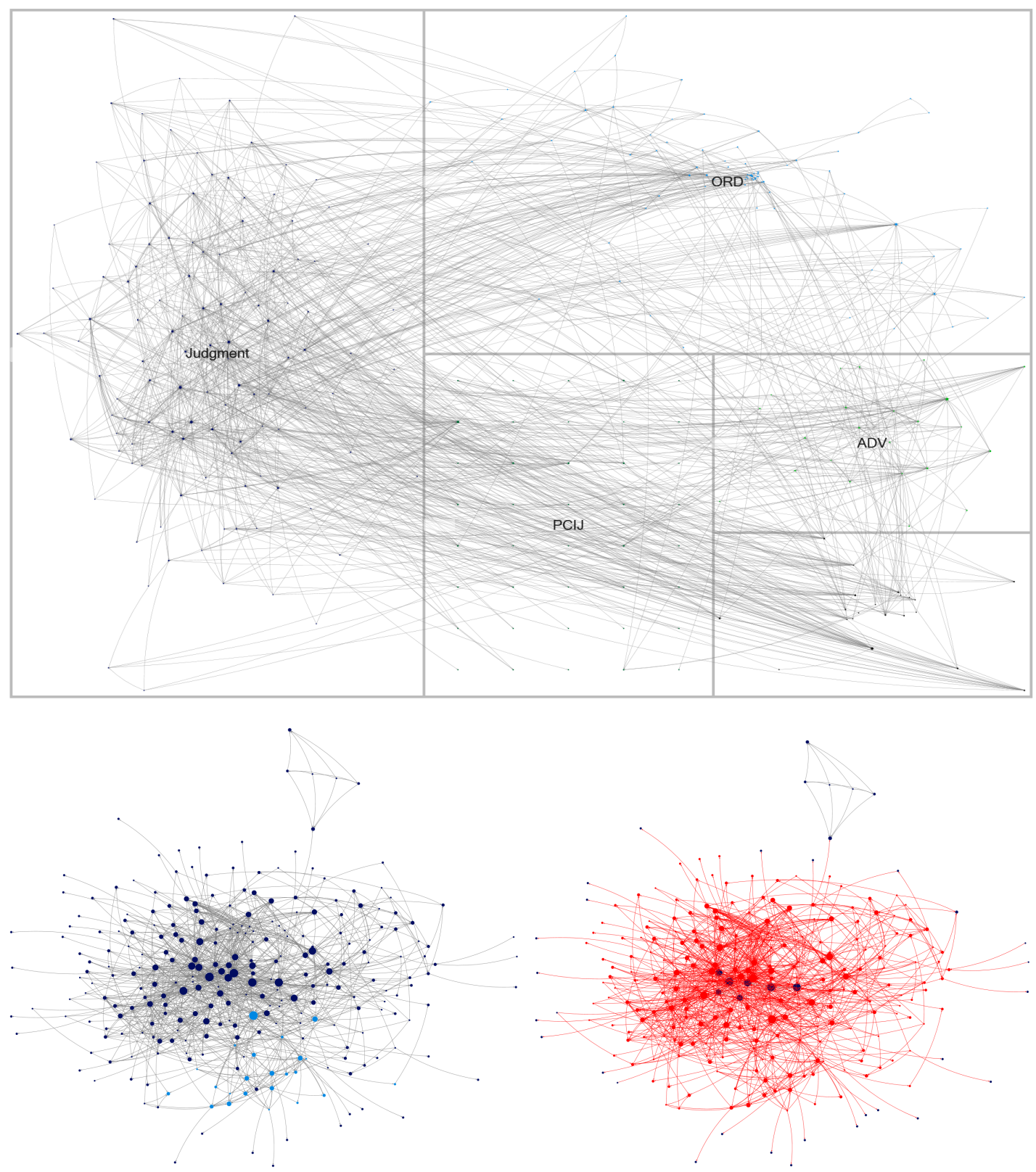

Figure 15: Above, forced clustering of decisions in various stages. Below, distribution of advisory opinions (light blue) and their overall connectedness to the main network.

2. Treaties and communities of case law in investment arbitration: The strategic use of precedent at the ECHR as a comparator

It is commonly said that one of the conceptual difficulties arising from international investment law is its arising from web of thousands of largely similar—though almost never wholly identical—bilateral investment treaties (BITs). Reliance on precedent in investment treaty arbitration has been famously discussed, alongside in pari materia interpretation, as one potential tool to depart from the bilateral architecture of the investment regime, thereby re-building its foundations with a multilateral outlook. ${ }^{76}$ Potential benefits envisaged under this lens include increased consistency in the interpretation of broadly similar treaty standards, which in turn fosters, the argument goes, trust in the system by its users.

\footnotetext{
${ }^{76}$ Stephan W Schill, The Multilateralization of International Investment Law (Cambridge University Press 2009) Chapter VII.
} 
Yet, the argument has been made, and convincingly, that one such use of previous decisions may amount to an undesirable overriding of state consent, especially where treaties are significantly different, ${ }^{77}$ potentially serving as one of the ways in which multinational corporations or powerful states progressively erode state consent to develop norms that better serve their interests. ${ }^{78}$ This approach has been also indirectly criticised by certain tribunals, which have defended their mandates as inherently 'case-specific'. 79

To what extent, then , do investment tribunals cite decisions taken under a different treaty framekwork? The hypothesis may be set out that citations to cases arising from the same treaty bases might be preferable from the point of view of an adjudicator preoccupied with showing observance of the mandate attributed to it, as well as more useful due to the higher similarity of the standards to be applied. ${ }^{80}$ Yet, identity of treaty basis only seems to be a significant variable in the making of communities of case law for a few agreements. For example, $20.29 \%$ of the invoked by tribunals arbitrating under the Energy Charter Treaty (ECT) were also litigated under the same treaty basis; these identity figures are 35.90 for the 1991 Argentina - US BIT, 38.89\% for NAFTA Chapter XI tribunals.

It is possible to offer a comparison by considering the citation network of the ECHR as a baseline. Already in 2011 Lupu and Voeten considered the question of whether the Court used precedent in a way that suggested a desire for strategic and relativist legitimation, thus considering, inter alia, the possibility that the political, legal and cultural characteristics of the respondent state, as well as the number of cases on a particular issue, would inform the number and selection of citations..$^{81}$ In order to do so, they considered the variations within the communities of case law that they had isolated. In order to provide an even more straightforward baseline, here the question is considered of whether the question of whether identity of the respondent state was a significant variable affecting the selection of precedents. A custom dataset was created including over 130,000 citations contained in 10,035 ECHR judgments, building on the hypothesis that precedents concerning the respondent state might be more persuasive or otherwise desirable, more relevant when the case concerns a systemic problem, or otherwise consistent with considerations informed by the margin of appreciation principle.It was found that only in the case of four respondent states (out of forty) there was no preponderance of precedents issued against that state. ${ }^{82}$

In other words, identity of treaty basis in international investment arbitration is not nearly strong a correlation. Yet, where frequently litigated treaties are concerned, citations of decisions arising from a very similar treaty basis are almost assured. This suggest that the question could be not so much one of contextindependence of the authority of previous decisions, but rather one of availability heuristics, warranting further study.

\footnotetext{
${ }_{77}$ Wolfgang Alschner (ed), State-Driven Change in International Investment Law and Its (Uncertain) Impact on Investor-State Arbitration: An Empirical Big Data Analysis (Graduate Institute of International and Development Studies 2015) $301 \mathrm{ff}$ (on file with the author).

${ }_{78} \mathrm{M}$ Sornarajah, The International Law on Foreign Investment (3rd ed, Cambridge University Press 2010) 52.

79 Glamis Gold, Ltd. v. The United States of America, UNCITRAL, Final Award, 8 June 2009, para 8.

80 The argument would probably hold even in the case of a 'similar BIT'. See AWG Group Ltd. v. Argentine Republic, UNCITRAL, Decision on Liability, 30 July 2010, para. 144.

${ }^{81}$ Lupu and Voeten (n 42) 417.

${ }^{82}$ See data in the Appendix.
} 

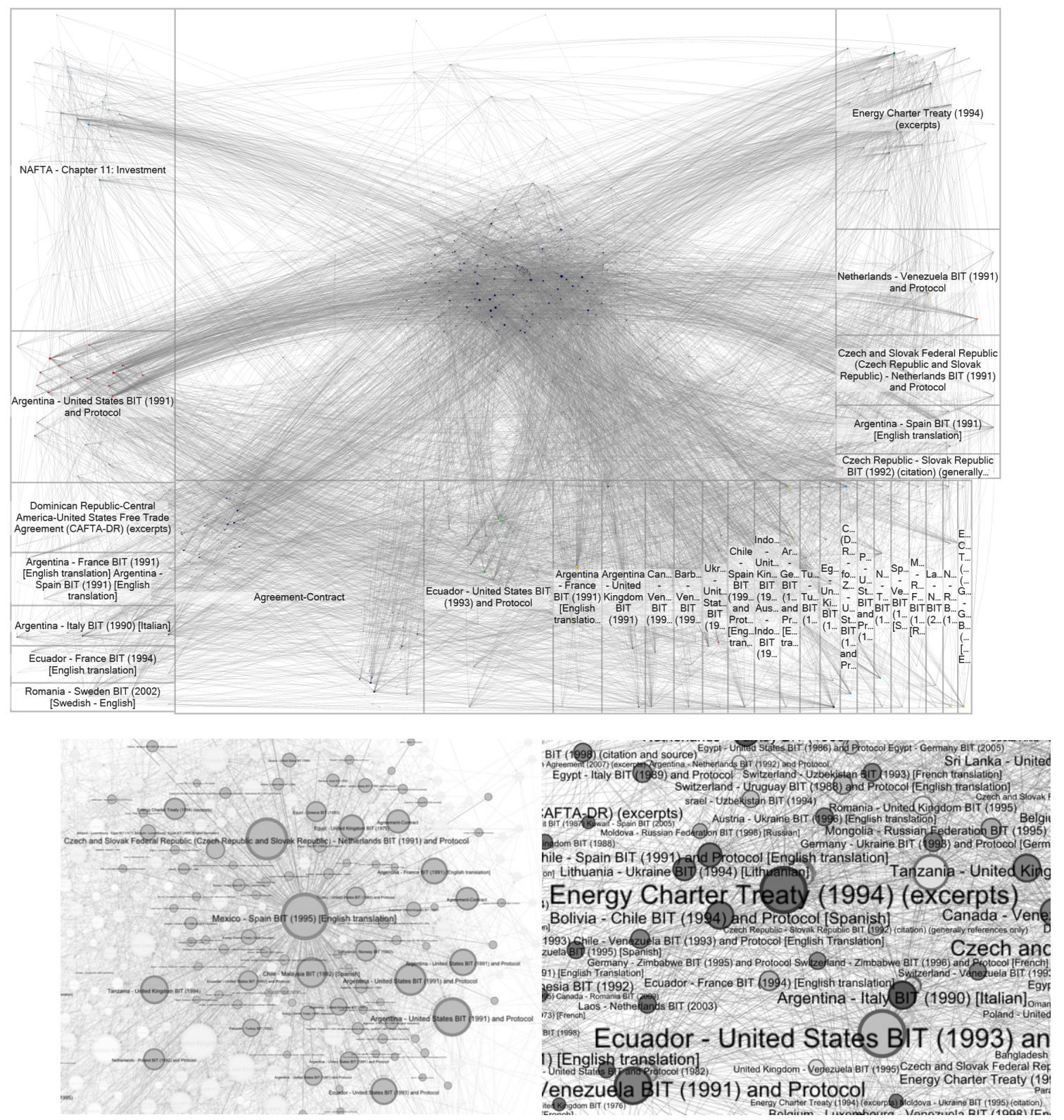

Figure 16:Above: portion of the investment citation network, with forced clustering by treaties (the largest cluster contains all the nodes associated with treaties linked to five or less nodes). Below: The Maffezini ego network, viewed through the lens of treaties. 


\section{Paragraphs, propositions, and legacies: Higher granularity as a key the path of precedent}

\section{A. Consider North Sea Continental Shelf: Problems in the unpacking of a precedent}

Precedents tend to serve well as shortcuts. To an international lawyer, mentions of Lotus, Mavrommatis, Monetary Gold, or Salini will inevitably evoke a follow-up term such as, respectively, 'presumption', 'test', 'principle', and 'criteria'. The assumption that a previous decision should be no more than a one-trick pony is certainly foreign to scholars and practitioners alike. Yet, there is something to be said about the tendency of precedent to be reduced to increasingly simple and general propositions-the very hallmark of its usefulness and efficiency — and the processes that allows this transformation. In other words, just for how many reasons can a previous decision be cited, and are these reasons always static?

The example of the North Sea Continental Shelf cases comes to mind. ${ }^{83}$ To most international lawyers, this is simply the case about the identification and ascertainment of rules of customary international law. Yet, a quick look into the approach of the ICJ to its citation reveals a different picture, with a grand total of 36 unique paragraphs of the Judgment being referenced by 26 other decisions. In only two is the Judgment invoked as an authority on questions of customary international law at issue. This finding, in and by itself, speaks volumes as to the ICJ's own attitude towards continuous engagement in system-design. ${ }^{84}$

Thus, just as references to cases may provide a good proxy for a deeper understanding of the use of precedent, references to individual paragraphs may provide important insights. ${ }^{85}$ One such analysis may provide, first, a deeper understanding of the current citation practices of international adjudicators and the mindset that drives them; second, it may challenge the assumption of centrality of certain highly-cited cases by disregarding their status as landmarks and breaking them down into the components that were actually used. To this end, a different heuristic approach was adopted by creating decision-to-paragraph networks. By doing so, it is possible to highlight the most significant sections of a popular precedent and thus identify what core propositions they are understood to stand for and their relative importance in the network. Error! Reference source not found. provides an example of one such network, including ICJ and ITLOS decisions. ${ }^{86}$

The data so obtained shows, quite unambiguously, that the power law applying in citation networks in general also characterises the number of paragraphs cited per each decision invoked. Thus, very few decisions are cited for many paragraphs, whereas most are considered a vessel for fewer propositions. It also shows that there might be significant differences between adjudicators in the way a power law of this kind plays out: for example, despite having issued a similar number of decisions the ICJ and the WTO AB differ significantly in the granularity of their use of the past: first, the latter tend to cite more paragraphs per cited precedent than the former-a pattern that also characterises much of the investment law network;

\footnotetext{
83 North Sea Continental Shelf (Federal Republic of Germany/Denmark; Federal Republic of Germany/Netherlands), Judgement of 20 February 1969, ICJ Reports 1969, p. 3.

${ }^{84}$ See generally Jean d'Aspremont, 'The International Court of Justice and the Irony of System-Design' Journal of International Dispute Settlement <https://academic.oup.com/jids/article/doi/10.1093/jnlids/idw020/2525397/The-International-Court-ofJustice-and-the-Irony> accessed 29 March 2017; See also the general argument made in Serena Forlati, The International Court of Justice (Springer International Publishing 2014) < http://link.springer.com/10.1007/978-3-319-06179-5> accessed 21 July 2016.

85 Not all adjudicators follow reasonably precise citation practices. Some of them, as is well known, may resort more vague invocations of short names without any additional specification, and whether they refer to a specific proposition is difficult to determine automatically. It is submitted here that the large number of citations collected suffices for the present purposes.
} 
second, and perhaps more strikingly, the ICJ is rather unique in the panorama of international adjudicators in that the most cited propositions are not always contained in what are, overall, the most cited precedents. ${ }^{87}$
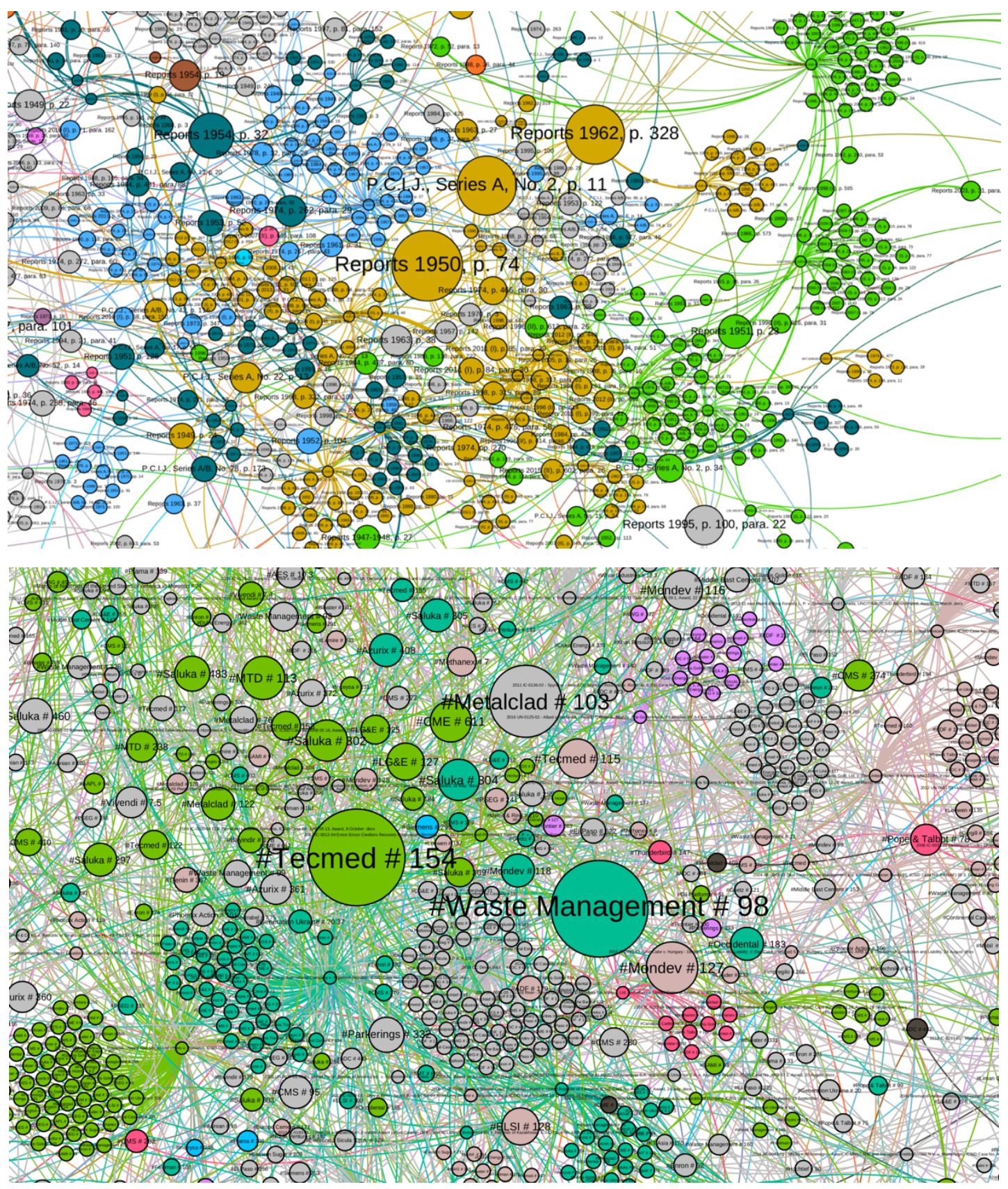

Figure 17:Above: Core of the ICJ / ITLOS case-to-paragraph network: Three core paragraphs on the concept of 'dispute' are visible at the centre. Below: core of the investment case-to-paragraph network, showing the core paragraphs on the Fair and Equitable Treatment analysis.

${ }^{87}$ See, for example, Interpretation of Peace Treaties, I.C.J. Reports 1950, p. 65 in the table below. 


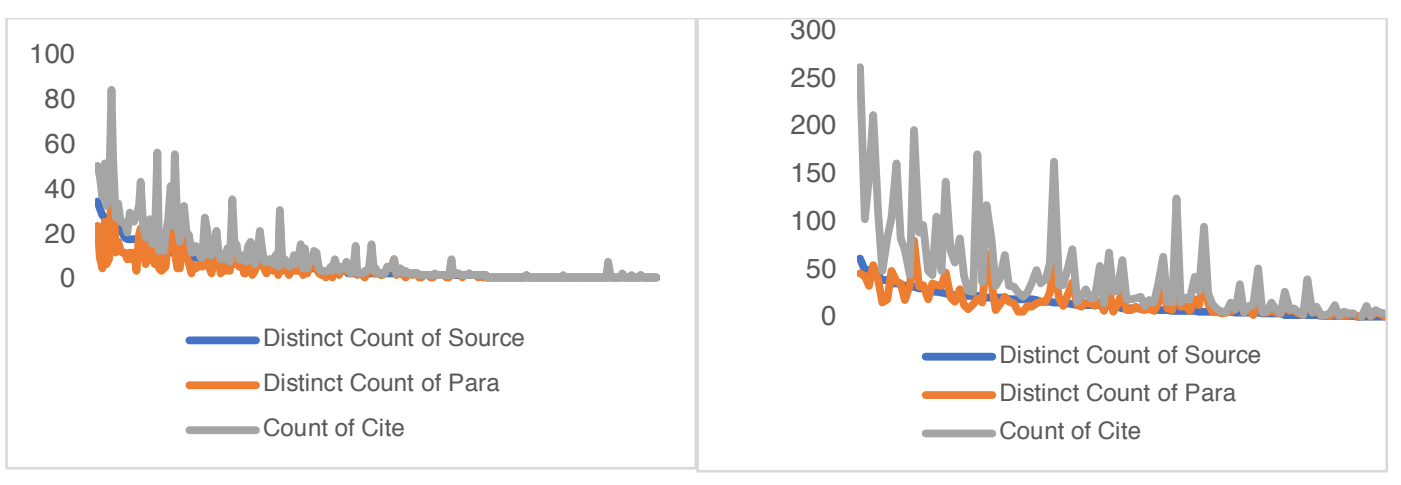

Figure 18: Distribution of numbers of unique paragraphs cited for each PCIJ/ICJ (left) and AB (right) precedent

Table 2: Comparison between in-degree scores (citations) and number of paragraphs cited

\begin{tabular}{|c|c|c|c|c|c|c|c|}
\hline CITED DECISION & $\begin{array}{c}\text { UNIQUe } \\
\text { Page/Para }\end{array}$ & $\begin{array}{l}\text { UNIQUE } \\
\text { SOURCES }\end{array}$ & Cites & Cited DECISION & Cites & $\begin{array}{l}\text { UNIQUE } \\
\text { PARAS }\end{array}$ & $\begin{array}{l}\text { UNIQUE } \\
\text { SOURCES }\end{array}$ \\
\hline Reports 1969 , p. 3 & 43 & 28 & 88 & EC - Hormones & 263 & 46 & 62 \\
\hline $\begin{array}{l}\text { Reports 1982, p. } \\
18\end{array}$ & 34 & 13 & 56 & US - Shrimp & 103 & 44 & 50 \\
\hline Reports 1986, p. 3 & 43 & 26 & 55 & $\begin{array}{l}\text { Australia - } \\
\text { Salmon }\end{array}$ & 147 & 33 & 50 \\
\hline $\begin{array}{l}\text { Reports 1984, p. } \\
392\end{array}$ & 27 & 29 & 53 & US - Carbon Steel & 213 & 55 & 48 \\
\hline $\begin{array}{l}\text { Reports 1986, p. } \\
554\end{array}$ & 23 & 17 & 44 & EC - Bananas & 109 & 39 & 44 \\
\hline $\begin{array}{l}\text { Reports 1985, p. } \\
13\end{array}$ & 25 & 13 & 43 & India - Patents & 49 & 16 & 39 \\
\hline $\begin{array}{l}\text { Reports 1974, p. } \\
253\end{array}$ & 24 & 27 & 43 & $\begin{array}{l}\text { US - Wheat } \\
\text { Gluten }\end{array}$ & 84 & 19 & 39 \\
\hline $\begin{array}{l}\text { Reports 2009, p. } \\
61\end{array}$ & 31 & 7 & 40 & US - FSC & 105 & 49 & 36 \\
\hline $\begin{array}{l}\text { Reports 1950, p. } \\
65\end{array}$ & 5 & 28 & 39 & Canada - Aircraft & 162 & 38 & 36 \\
\hline $\begin{array}{l}\text { Reports 1973, p. } \\
166\end{array}$ & 22 & 9 & 37 & EC-Bed Linen & 83 & 36 & 35 \\
\hline $\begin{array}{l}\text { Reports 2001, p. } \\
466\end{array}$ & 20 & 20 & 35 & Korea - Dairy & 71 & 18 & 33 \\
\hline
\end{tabular}




\section{A. The aggregate dimension: Growing number of propositions for which cases are cited}

Pinpoint references are a serviceable metric to track the number of propositions for which a certain precedent is cited. An analysis of the data provides a first important result: with the passage of time, this number grows steadily. Figure 19: Unique paragraphs cited for each ICJ decision; below, AB reports cited per year and unique paragraphs cited, below, provides a graphical representation of the phenomenon, comparing the number of total citations (Cite), the unique number of case citations (Target), and the unique number of pinpoint citations made (Page/Para). Naturally, as Lord Wright put it, precedents become what they are because decision-makers interrogate themselves as to whether the problem they are currently facing had not already arisen in the past. ${ }^{88}$ However, coupled with the large number of references to relatively old decisions discussed above, ${ }^{89}$ the ever-increasing number of paragraphs referenced in the same containers, is suggestive, if not of a tendency to rummage through old possessions for a solution, of the perceived need to affirm the coherence between the current decisions and the body of jurisprudence established before it.

Patterns of this kind may be ascribed in part to arguments deployed by the parties in their pleadings. However, the very large number of specific propositions invoked is also highly suggestive of a higher involvement of adjudicators' bureaucracies. That clerks and secretariat personnel will be tasked with finding the necessary references is an open secret among those with experience of international courts. ${ }^{90}$ Though the point is perhaps conjectural, a higher number of consonant citations is more suggestive of delegated work than of serious engagement with previous decisions.

\footnotetext{
${ }^{88}$ Lord Wright, 'Precedents*' (1943) 8 The Cambridge Law Journal 118, 144.

${ }^{89}$ See supra, section 1.II.A.2.

90 Hugh Thirlway, 'The Drafting of ICJ Decisions: Some Personal Recollections and Observations' (2006) 5 Chinese Journal of International Law 15, 18 (recalling the many times he highlighted inconsistencies with previous decisions in the Judge's reasoning); Tommaso Soave, 'The Politics of Invisibility: Why Are International Judicial Bureaucrats Obscured from View?' (Social Science Research Network 2017) SSRN Scholarly Paper ID $3180735<$ https://papers.ssrn.com/abstract=3180735> accessed 6 February 2019.
} 

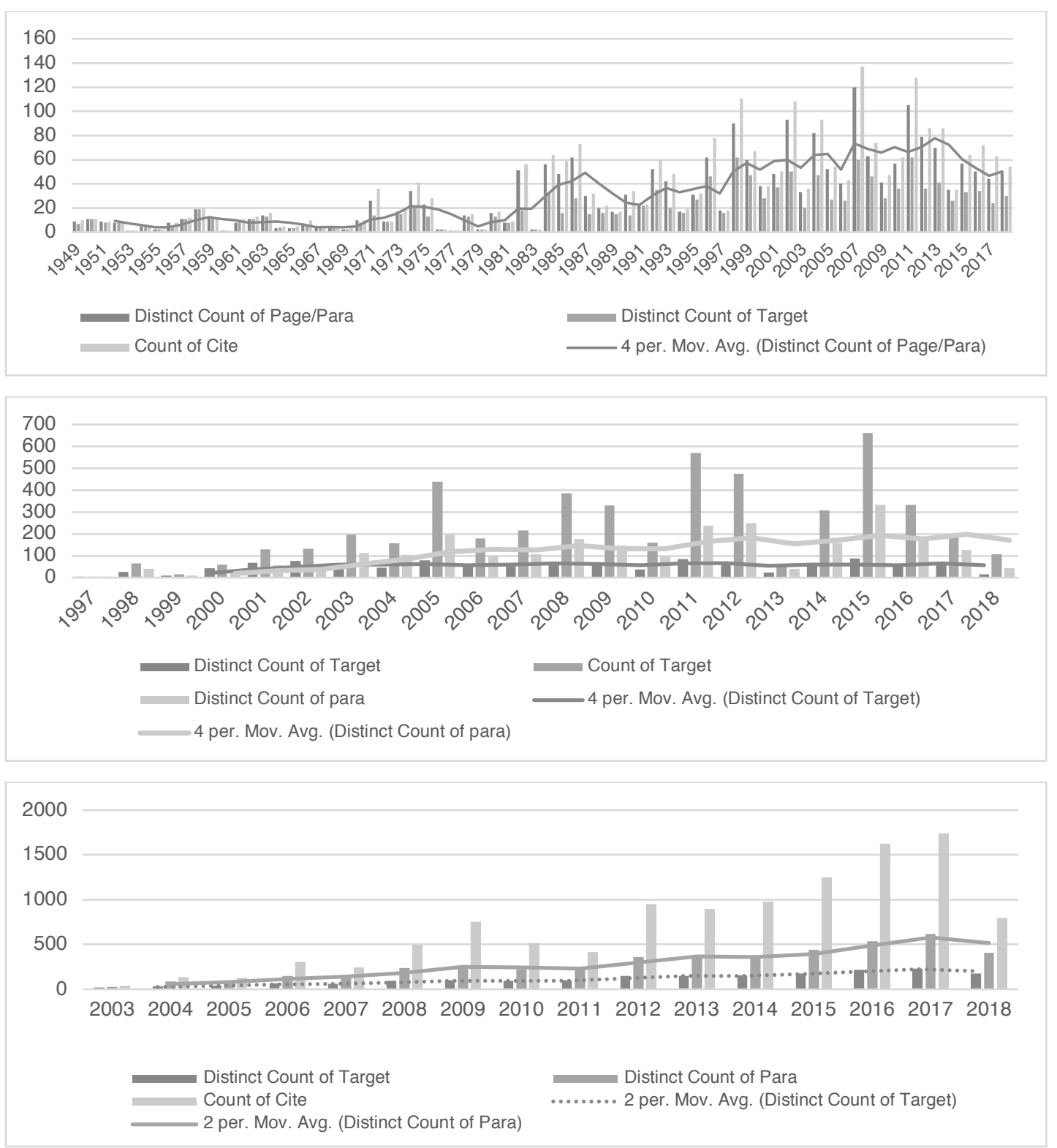

Figure 19: Unique paragraphs cited for each ICJ decision; below, AB reports cited per year and unique paragraphs cited

\section{B. Highly cited paragraphs}

The argument was made above that the importance, in citation and network centrality terms, of a given decision is very much a function of the adjudicator's docket. By the same token, it is submitted here that the citation of certain propositions contained in precedents does not depend merely on the similarity of the substantive legal issues, broadly considered, in the cases at stake, but rather on the systemic necessity of the proposition invoked. The analysis carried here points, quite unequivocally, to those propositions that do not simply have a significant scope of application (a description that holds true for many procedural principles), ${ }^{91}$ but rather a foundational importance for each adjudicator's function.

91 Thus, Crawford maintains that the ICJ may be seen as following some doctrine of precedent in matters of procedure. See Ian Brownlie and James Crawford, Brownlie's Principles of Public International Law (Oxford University Press 2012) 38-39. 


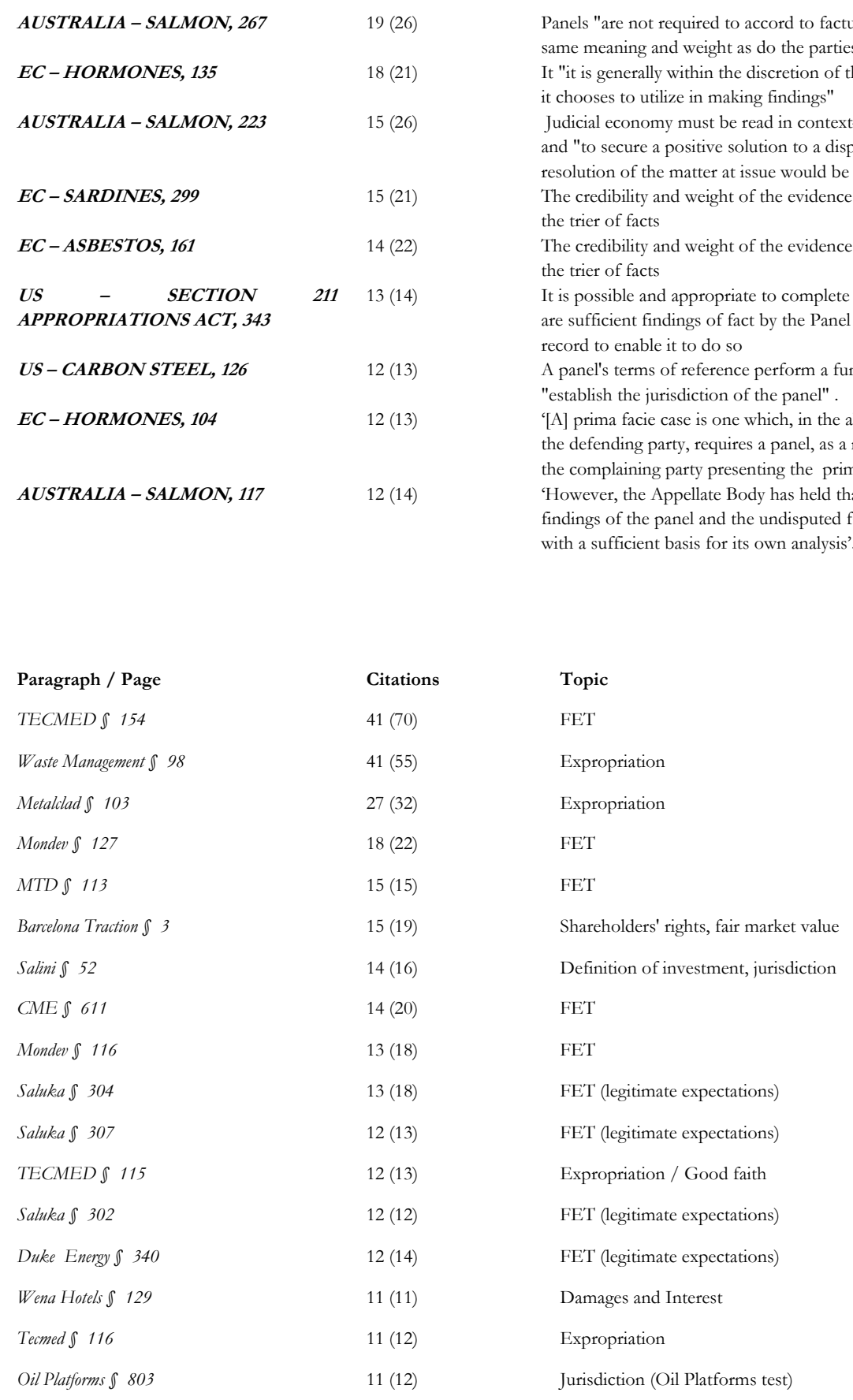

\section{Highly citing paragraphs: Review or rhetoric?}

Just as the most cited paragraphs or pages may shed light on the nature of the problems most commonly faced by international adjudicators, and, inevitably, on the centrality of the propositions that they embody, important insights may be drawn from an analysis of the most citing paragraphs, that is to say, the ones that contain the highest number of citations. For example, they might contribute to identifying areas where a common thread of authoritative decisions has reached the same conclusion-jurisprudence constante, so to speak —or an attempt by the drafter to persuade its audience that this is the case. In a partial alternative, they might be symptomatic of a greater need to ground a statement in a number of authorities, in an attempt, 
for example, to portray a novel proposition as coherent with previous jurisprudence, or to make a critically controversial proposition appear supported by a sizeable number of authoritative voices in a field ${ }^{94}$ - [ [] $]$ ists lend conviction by sonorous allusion'. ${ }^{95}$ Thus, it is common for citations to precedent to be read as legitimacy-enhancing devices, especially where no obligation to follow them exists, and as a way to convey confidence in foundational principles on which the work of the adjudicator is dependent. In order to test this hypothesis, the paragraphs citing the highest number of precedents were collected.

Once again, starting with the ICJ proves instructive. Thus, in DRC $v$ Rwanda the Court provided seven references for the proposition that an objection based on non-fulfilment of the preconditions set out in the compromissory clauses was in fact an objection to jurisdiction, rather than to the admissibility of the claim;96 six were made to affirm the hermeneutic argument that negotiations were to be conducted in good faith despite the lack of one such express requirement in a treaty clause; ${ }^{97}$ five reference supported the Court's argument that non-participation to the proceedings before it has a negative impact on the sound administration of justice, and that 'non-participation of a party in the proceedings at any stage of the case cannot, in any circumstances, affect the validity of its judgment'. ${ }^{8}$ Yet, the Court also made use of this technique to carry out reviews of the available materials, for example to establish that a particular principle was well established in international law. ${ }^{99}$

On its part, the WTO AB did so to support its approach in scenarios likely to attract controversy-for example, in the context of responding, generally in the negative, to requests to complete a panel's legal analysis, which is known to raise 'concerns regarding the jurisdiction and mandate of the Appellate Body, the extent to which it may engage in factual assessment, and due process in WTO dispute settlement proceedings'. ${ }^{100}$ However, an analysis of these citation patterns also reveals more utilitarian uses, where a string of references is more likely to have been attached to the relevant paragraph for efficiency reasons, thus avoiding the need of deploying a full analysis of the relevant issues. ${ }^{101}$ This use of the technique may also fall in what may be defined a 'we told you so' logic. However, rather than target the parties to the proceedings, the past is used to send a message to the panels, thereby cementing the AB's authority. ${ }^{102}$

The approach of arbitral tribunals is, instead, highly variable. Thus, strings of precedents have been used to bolster otherwise pithy introductory statements setting out the framework for analysis (for example, on FET), ${ }^{103}$ but also to contextualise a tribunal's approach as consistent with previous decisions (tipically, on

\footnotetext{
94 Douglas Walton, Appeal to Expert Opinion: Arguments from Authority (Penn State Press 2010) 218-219.

${ }^{95}$ Lowenthal (n 8) 343.

96 Armed Activities on the Territory of the Congo (New Application : 2002) (Democratic Republic of the Congo v. Rwanda), Jurisdiction and Admissibility, Judgment, I.C.J. Reports 2006, p. 6, at 39, para. 88.

97 Application of the Interim Accord of 13 September 1995 (the former Yugoslav Republic of Macedonia v. Greece), Judgment of 5 December 2011, I.C.J. Reports 2011, p. 644, at 44, para. 131.

98 Military and Paramilitary Activities in und against Nicaragua (Nicaragua v. United States of America). Merits, Judgment. I.C.J. Reports 1986, p. 14, at 23, para. 27.

${ }_{99}$ Land and Maritime Boundary between Cameroon and Nigeria, Preliminary Objections, Judgment, I.C.J. Reports 1998, p. 275, at 296, para. 38.

100 Alan Yanovich and Tania Voon, 'Completing the Analysis in WTO Appeals: The Practice and Its Limitations' (2006) 9 Journal of International Economic Law 933, 933. Appellate Body Report, US - Section 211 Appropriations Act, para. 384 (19 citations); Appellate Body Report, US - Continued Zeroing, para. 349 and Appellate Body Report, EC - Asbestos, para. 78 (both with 10 citations). ${ }^{101}$ For example, to unpack what Article 11 DSU requires: see Appellate Body Report, Brazil-Retreaded Tyres, para. 85 (14 citations); Appellate Body Report, EC and certain member states - Large Civil Aircraft, para 1317 (15 citations).

102 See, for example, Appellate Body Report, Japan - Apples

103 Murphy Exploration and Production Company International v. Republic of Ecuador [I], PCA Case No. 2012-16, Partial Final Award, 6 May 2016, para. 247.
} 
cost allocation or interest), especially where discretion was envisaged. ${ }^{104}$ In other instances citations appear to be nothing more than an acknowledgment of the parties' arguments, ${ }^{105}$ and only occasionally they appear to form part of a broader justificatory effort. ${ }^{106}$

\section{Other tribunals run by international lawyers as control}

Some dispute settlement mechanisms may not fit traditional definitions of international adjudicators, and yet their analysis, however brief, may proves instructive: first, they may have served as a milestone towards the creation of a more modern form of dispute settlement—such is, according to many, the relationship between the Iran-US Claims Tribunal (IUSCT) and the entire field of international investment arbitration; 107 second, and perhaps more crucially, a tribunal may be only loosely construed as applying international law', 108 but still be significant for the study of public international law adjudication due to the presence of a common core in the composition of their benches, where a great number of international lawyers have sat: this is certainly the case with regards to the IUSCT, but analogous considerations can be made for CAS arbitration, as well as for the less investigate WBAT. ${ }^{109}$ In other words, it may be asked whether decisionmaking practices such as the one considered here are dependent on the specifics of the particular adjudicator, or, conversely, linked to the inclinations, culture, habits of a number of distinguished members; third, all of these tribunals have been often described in the literature as being, to varying degrees, precedent-driven. ${ }^{110}$ Thus, whatever their ultimate weight, these factors certainly invite a comparison, which

104 Burlington Resources Inc. v. Republic of Ecuador, ICSID Case No. ARB 08 5, Decision on Reconsideration and Award, 7 February 2017, para. 619; Crystallex International Corporation v. Bolivarian Republic of Venezuela, ICSID Case No. ARB(AF) 11 2, Award, 4 April , para. 935.

105 Tulip Real Estate and Development Netherlands B.V.v. Republic of Turkey, ICSID Case No. ARB 11 28, Decision on Annulment, 30 December 2015, para. 75

106 Ioan Micula and others v. Romania, ICSID Case No. ARB 05 20, Decision on Annulment, 26 February 2016, para. 138 (on the Committee's power to reconstruct an award's reasons).

${ }^{107}$ See generally David D Caron, 'The Nature of the Iran-United States Claims Tribunal and the Evolving Structure of International Dispute Resolution' (1990) 84 American Journal of International Law 104; Charles Nelson Brower and Jason D Brueschke, The Iran-United States Claims Tribunal (Martinus Nijhoff Publishers 1998); Christopher R Drahozal and Christopher S Gibson, The IranU.S. Claims Tribunal at 25: The Cases Everyone Needs to Know for Investor-State \& International Arbitration (Oxford University Press 2007). 108 Rule 45 of the CAS Code of Procedural Rules provides that ' $[\mathrm{t}]$ he Panel shall decide the dispute according to the rules of law chosen by the parties or, in the absence of such a choice, according to Swiss law. The parties may authorize the Panel to decide ex aequo et bono'. See also Leonardo VP de Oliveira, 'Lex Sportiva as the Contractual Governing Law' (2017) 17 The International Sports Law Journal 101. Less specific directives are in place for the World Bank administrative tribunal, though it is well understood that international administrative tribunals 'rely on several sources, including the employment contract, internal law of international organizations, and generally recognized principles of international administrative law'. See Peter C Hansen, 'The World Bank Administrative Tribunal's External Sources of Law: The Next Chapter (2006-2010) (Part I)' (2012) 11 The Law \&amp; Practice of International Courts and Tribunals 199. Article V of the Claims Settlement declaration, reproduced in Article 33 of the IUSCT Statute, which directs the Tribunal to 'decide all cases on the basis of respect for law, applying such choice of law rules and principles of commercial and international law as the Tribunal determines to be applicable, taking into account relevant usages of the trade, contract provisions and changed circumstances'. See John R Crook, 'Applicable Law in International Arbitration: The IranU.S. Claims Tribunal Experience’ (1989) 83 The American Journal of International Law 278; See also, on the relevance of party autonomy, Caron (n 107) 189.

109 The WBAT can boasts an exceptionally illustrious list of members, including former Judges (and Presidents) of the ICJ, such as Judges Jimenez de Arechaga, Ajibola, Schwebel, and Koroma, as well as many celebrated international lawyers and arbitrators, such as Prosper Weil, Elihu Lauterpacht, Francisco Orrego Vicuña, and Jan Paulsson.

110 On the WBAT, see Jan Paulsson, 'The Role of Precedent in Investment Arbitration' in Katia Yannaca-Small (ed), Arbitration under International Investment Agreements: A Guide to the Key Issues (2010) 718. On CAS, see Gabrielle Kaufmann-Kohler, 'Arbitral Precedent Dream, Necessity or Excuse?’ (2007) 23 Arbitration International 357, 365-366; See also, generally, Lorenzo Casini, 'The Making of a Lex Sportiva by the Court of Arbitration for Sport', International Judicial Lawmaking (Springer 2012); Annie Bersagel, 'Is There a Stare Decisis Doctrine in the Court of Arbitration for Sport-An Analysis of Published Awards for Anti-Doping Disputes in Track and Field' (2012) 12 Pepp. Disp. Resol. LJ 189. 
OTHER TRIBUNALS RUN BY INTERNATIONAL LAWYERS AS CONTROL

is especially interesting in light of the fact that the general orthodoxy on judicial decisions as 'subsidiary means' cannot be simply reproduced in these different contexts. 

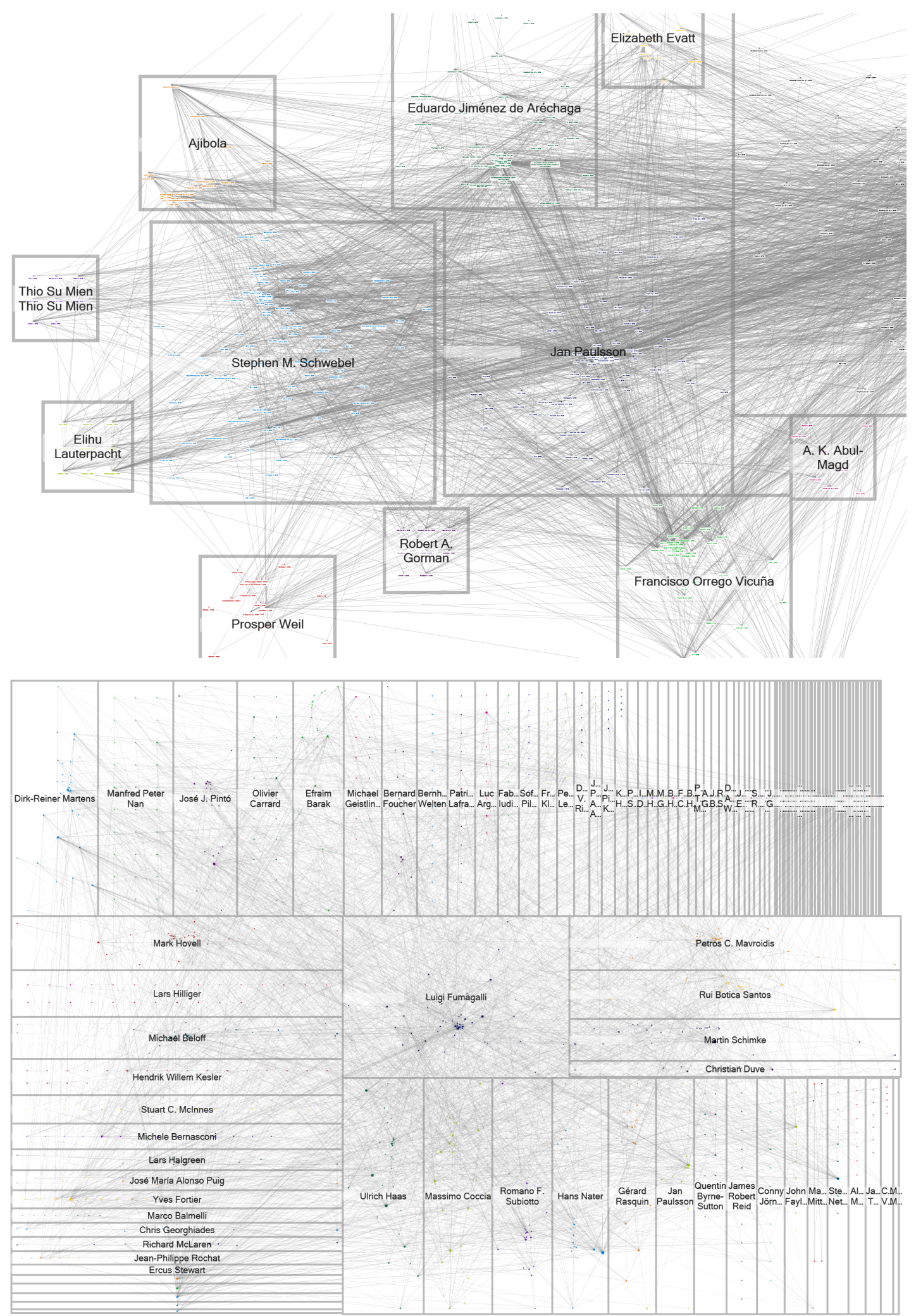

Figure 20: WBAT and CAS citation networks with forced clustering to bighlight the contribution of prominent international lanyers 


\section{A. Control tribunals exhibit similar network features}

An analysis of the IUSCT, WBAT and CAS citation networks would reveal characteristics that are both similar to the ones of the ones forming the main object of this study and consistent with the models associated with common law jurisdictions. Thus, all the networks considered here score consistently in the areas of density, degree distributions, clustering, and average path length, consistently with the anecdotal accounts of a growing relevance of previous decisions in the day-to-day operation of these bodies.

$\begin{array}{llll} & \text { IUSCT } & \text { WBAT } & \text { CAS } \\ \text { Density } & 0.003 & 0.011 & 0.004 \\ \text { Avg. Path Length } & 1.352 & 3.53 & 3.616 \\ \text { Avg. Clustering Coefficient } & 0.005 & 0.153 & 0.111 \\ \text { Avg. Degree } & 3.067 & 6.141 & 3.406\end{array}$

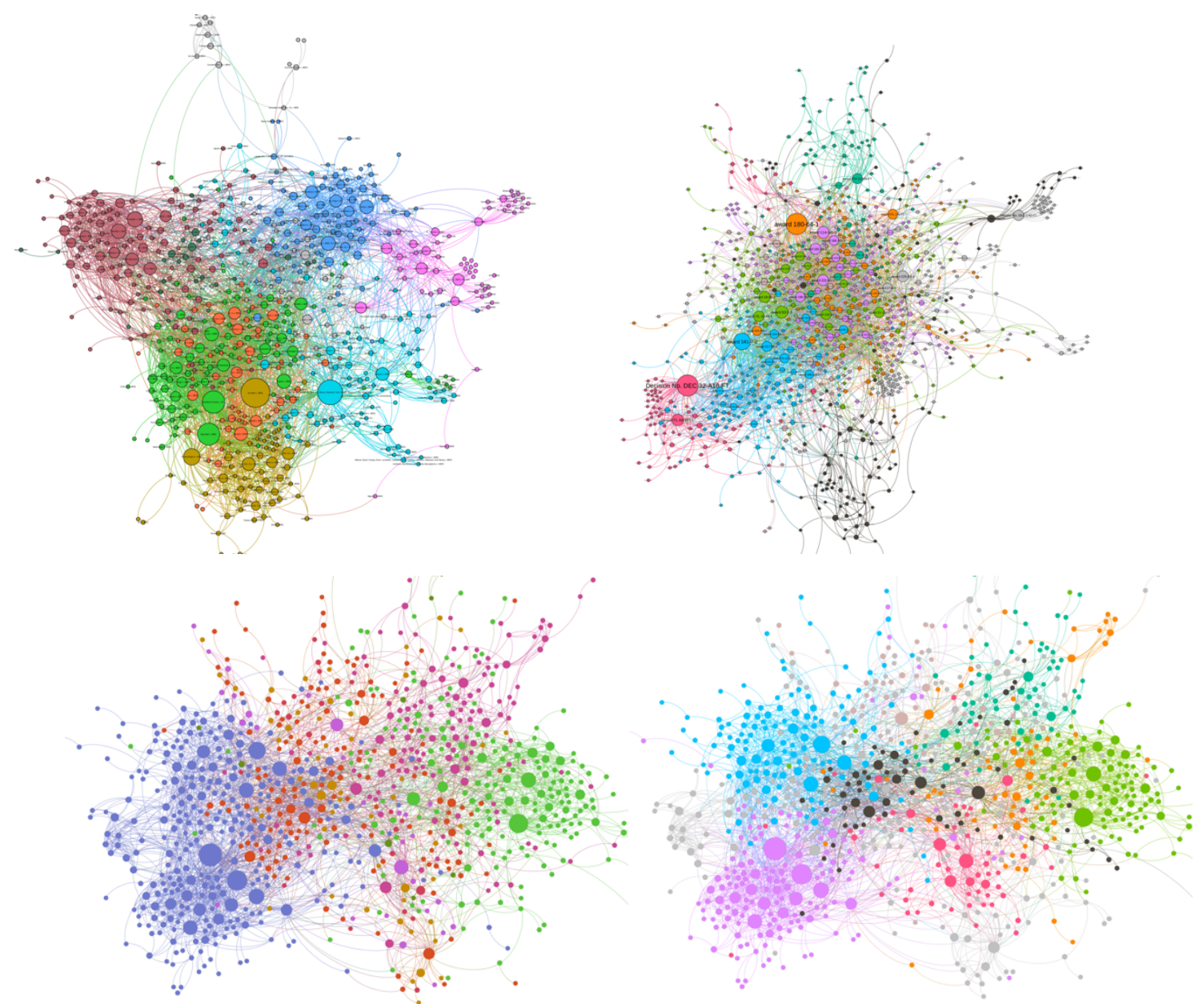

Figure 21: Top left is the WBAT network; top right, the IUSCT. Different shades follow modularity class communities. Below, cases decided by CAS Tribunals. On the left, different shades represent matters dealt with: doping, disciplinary disputes, contract, transfers, all other disputes. On the right, they represent modularity class communities. 


\section{B. Most cited and most citing paragraphs also appear to follow familiar dynamics}

Similarly, an analysis of the jurisprudence of the control tribunals confirms that constant reliance on the same paragraphs is likely to provide evidence of key, foundational propositions which are both necessary for the streamlining of the tribunal's procedure and the definition of the adjudicator's role vis-à-vis its institutional context. For example, ranking the most cited paragraphs in the jurisprudence of the IUSCT, reveals a significant re-use of texts concerning questions of nationality, ${ }^{111}$ subject-matter jurisdiction and counter-claims, ${ }^{112}$ indirect expropriation, ${ }^{113}$ costs, ${ }^{114}$ and governmental control. ${ }^{115}$ Performing a similar analysis on the body of jurisprudence of the WBAT, it is possible to appreciate similar patterns. Thus, the most cited paragraphs point to widely used tests, such as that for abuse of discretion; ${ }^{116}$ principles of executive deference; ${ }^{117}$ guarantees of due process; ${ }^{118}$ the exhaustion of internal remedies; ${ }^{119}$ burden of proof; 120 and the scope of its review. ${ }^{121}$

It is not possible to carry out an identical review for the CAS, as decisions are more rarely cited with pinpoint precision, but a review of the most cited awards nevertheless allows to identify a number of key propositions and materials. These include criteria concerning the quantum of discretion enjoyed by, and correlative deference to be paid to, disciplinary bodies in the determination of sanctions to athletes; ${ }^{122}$ the standard of review in addressing such sanctions; ${ }^{123}$ the grounds for termination of contract and the criteria for determining the existence of a 'just cause'-an issue that also calls into question the law applicable to the dispute; ${ }^{124}$ the general policies concerning the fight against doping as possible justifications for strict liability standards; ${ }^{125}$ the applicability of the tempus regit actum principle as a safeguard against retroactive application of disciplinary rules; ${ }^{126}$ as well as the scope of principles of procedural fairness. ${ }^{127}$

Most citing paragraphs, too, are instructive. The highest-citing paragraph in IUSCT jurisprudence features a staggering 15 citations to confirm its adherence to previous practice; ${ }^{128}$ yet, there are also includes instances where the Tribunal sought to reinforce its legitimacy by explaining the grounds that would divest it of the

111 Case No. A18, Decision No. DEC 32-A18-FT, p. 25.

112 T.C.S.B. and Islamic Republic of Iran, Award No. 114-140-2, p. 24 (16 March 1984).

113 Tippetts, Abbett, McCartby, Stratton and TAMS-AFFA, et al., Award No. 141-7-2, at 10-11 (29 June 1984),.

114 Sylvania Tecbnical Systems, Inc. and The Government of the Islamic Republic of Iran, Award No. 180-64-1, pp. 35-38 (27 June 1985).

115 Ultrasystems, Inc. and Islamic Republic of Iran et al., Partial Award No. 27-84-3, pp. 8-9 (4 March 1983),.

116 Marshall, Decision No. 226 [2000], para. 21 (46 citations); Desthuis-Francis, Decision No. 315 [2004], para. 19 (44 citations); De Raet, Decision No. 85 [1989], para. 67

117 For example, on the determination of whether a staff member's performance is satisfactory being a matter for the Respondent to decide, Saberi, Decision No. 5 [1981], para. 24 (32 citations).

118 Garcia-Mujica, Decision No. 192 [1998], para. 19 (31 citations); Samuel-Thambiah, Decision No. 133 [1993], para. 32 (25 citations).

119 Berg, Decision No. 51 [1987], para. 30 (28 citations); Setia, Decision No. 134 [1993], paragraph 23 (25 citations).

120 Dambita, Decision No. 243 [2001], para. 21 (26 citations).

121 Koudogbo, Decision No. 246 [2001], para. 18 (25 citations).

122 Advisory opinion CAS 2005/C/976 \& 986 Fédération Internationale de Football Association (FIFA) \& World Antidoping Agency (WADA), 2006 (66 citations).

123 CAS 2005/A/830 S. v. FINA, 2005 (57 citations).

124 CAS 2006/A/1180 Galatasaray SK v. Frank Ribéry \& Olympique de Marseille, 2007 (55 citations).

125 CAS 2006/A/1100 E. v. Club Gariantepspor, 2006 (49 citations.)

126 CAS 2000/A/274 S. / Fédération Internationale de Natation (FINA), 2000 (42 citations).

127 CAS 98/211 B. / Fédération Internationale de Natation (FINA), 1999 (41 citations)

128 See Case No. A33, Decision No. 132-A33-FT, para. 40 ('The Tribunal does not understand the request of the United States that the Tribunal order Iran to replenish to be a request for a separate document... The Tribunal has done so in paragraph 45A below, with the understanding that the Tribunal's orders to the Parties are regularly phrased as requests'). A paragraph with 27 citations was contained in an annex to a decision and was thus discounted. 
jurisdiction to hear a claim. ${ }^{129}$ Conversely, the WBAT has often listed strings of precedent to present the jurisprudence on fairness according to staff principles, ${ }^{130}$ exhaustion of internal remedies, ${ }^{131}$ the Tribunal's general scope of review regarding sanctions, ${ }^{132}$ and time limits. ${ }^{133}$ CAS Tribunals, too, have stringed several references together when dealing with thorny questions such as the presumption of guilt of an athlete; ${ }^{134}$ the question of whether an athlete's negligence may qualify as 'significant' — with one example, in particular, being deployed in an extremely high profile case; 135 and to highlight the unity of jurisprudence on questions such as the scope of review, ${ }^{136}$ as well as on the issue of legitimation passive. ${ }^{137}$ Interestingly, however, some exceptions exist where the a number of precedents have been stringed together to highlight the inconsistency of the jurisprudence accrued to date. ${ }^{138}$

\section{Assessment}

In conclusion, the three fora under review display striking similarities to the ones considered in the previous sections. Thus, the results provide at least circumstantial evidence that the practice of referring to previous decisions is not entirely connected to the mandate, regime, and applicable law specific to any particular adjudicator, but might also be more generally entrenched within a broader community of lawyers engaged in the wider field of international dispute settlement. One such finding is consistent with accounts that have identified important connections between those who sit on the bench (and practice before) international adjudicators, and contributes to raising questions - which cannot possibly be addressed in these pagesregarding the idea of international and transnational lawyering and the impact of the social dynamics informing it. 139

\footnotetext{
129 Orton/McCullough Crane Company v. Iranian State Railways, Bank. Markazi Iran, Case No. 440, Award No. 484-440-3, para. 9 (10 citations).

130 CL, 2014 Decision No. 499, CL v. International Bank for Reconstruction and Development [2014], para. 499 (8 citations).

131 Decision No. 574 BI (Nos. 6 and 7) v. International Finance Corporation (Preliminary Objection) [2017], para. 30 (7 citations).

${ }^{132}$ CB v. International Bank. for Reconstruction and Development, Decision No. 476 [2013], para. 31 (6 citations).

133 Decision No. 520 Saad Abdulrazak Alrayes v. International Finance Corporation (Preliminary Objection) [2015], para. 54 (6 citations).

134 CAS 2001/A/317 A. / Fédération Internationale de Luttes Associées (FIL A), 2001, para. 39 (14 citations).

135 CAS 2016/A/4643 Maria Sharapova v. International Tennis Federation (ITF), 2016, para. 82 (11 citations).

136 CAS 2014/A/3621 JSC PFC Rostov v. Football Union Russia (RFU), 2015, para. 74 (8 citations, including references made in cited passages).

137 Arbitration CAS 2014/A/3553 FC Karpaty v. FC Zestafoni, 2014, para. 98 (9 citations).

138 CAS 2013/A/3256 Fenerbahçe Spor Kubibü v. Union des Associations Européennes de Football (UEFA), 2014, para. 275 (8 outward citations).

139 Yves Dezalay and Bryant G Garth, Dealing in Virtue: International Commercial Arbitration and the Construction of a Transnational Legal Order (University of Chicago Press 1998); Shashank P Kumar and Cecily Rose, 'A Study of Lawyers Appearing before the International Court of Justice, 1999-2012' (2014) 25 European Journal of International Law 893; David D Caron and others, Practising Virtue: Inside International Arbitration (Oxford University Press 2015); Joanna Jemielniak and Michal Kaczmarczyk, 'Sociology of Arbitration: New Tools for the New Times' (Social Science Research Network 2016) SSRN Scholarly Paper ID $2883065<$ https://papers.ssrn.com/abstract=2883065> accessed 8 February 2019; See also the reflections in Stephan W Schill, 'W(h)Ither Fragmentation? On the Literature and Sociology of International Investment Law' (2011) 22 European Journal of International Law 875.
} 


\section{Sketches of computational content and style analysis}

\section{A. Footnotes, again}

The position of citations in the main text of the decision or in the footnotes is the subject of significant scholarly and professional debates in some jurisdictions. In the United States, for example, some scholars have felt strongly that citations should be concentrated in the footnotes in order to make the text of the decisions accessible to lawyers and non-lawyers alike. ${ }^{140}$ Others have instead observed that intelligibility by legal professionals is of greater importance than striving for text that a layperson would actually read. ${ }^{141}$ The question may also arise of whether footnotes should be considered authoritative in their own right, ${ }^{142}$ and, more specifically, whether they should be considered as authoritative as whatever has been said in the main text of the decision.

The observation may be made in passing that style is never neutral: as Richard Posner suggests, 'no one speaks in footnotes and headings', ${ }^{143}$ and the use or avoidance of these devices have the result of raising or lowering the register of the decision-making it more syllogistic and resolute, as footnotes may allow shorter, hectoring sentences. ${ }^{144}$ An in-line citation might, depending on the context, diminish or amplify this effect. ${ }^{145}$ In other words, they may very well work as an aesthetic device. ${ }^{146}$ The point, however, whether or not placing a citation in a footnote might signal the same degree of engagement than its mention in the main text of the decision.

A relatively simple analysis suggests that there must be some difference: applying a series of greedy regular expressions, designed to catch anything from the official citation to the short title of the dispute, to a dataset of $131 \mathrm{AB}$ reports yields a grand total of 12,840 citations. Yet, once a more conservative file sectioning system is put in place, removing any text contained in the footnotes, only 559 citations may be found. In other words, the numbers drop by almost ninety-six percent.

\footnotetext{
140 Bryan Garner, The Winning Brief: 100 Tips for Persuasive Briefing in Trial and Appellate Courts (Third Edition, Oxford University Press 2014) 114.

141 Richard A Posner, 'Court Review: Volume 38, Issue 2 - Against Footnotes' [2001] Court Review: The Journal of the American Judges Association $24<$ http://digitalcommons.unl.edu/ajacourtreview/188> . It is worth pointing out, however, that Posner's views refer to shorter opinions, not necessarily a hundreds of pages long arbitral award. See also Antonin Scalia and Bryan A Garner, Making Your Case: The Art of Persuading Judges (West Publishing Company, College \& School Division 2008) 134-134; United States, Office of the Reporter of Decisions and Jack Metzler, The Supreme Court's Style Guide (2016) \ 1.1 .2 (discussing the implications of the practice as the 'bobblehead doll syndrome') .

${ }^{142}$ For a light-hearted, but illuminating account of the problem in American law see the single-word Robert A James, 'Are Footnotes in Opinions Given Full Precedential Effect?' [1999] The Green Bag; Consider, further, Simon Lester, 'Where Do Footnotes Belong?' (International Economic Law and Policy Blog) < https://worldtradelaw.typepad.com/ielpblog/2018/09/where-do-footnotesbelong.html> accessed 3 December 2018 (reflecting on Panel Report, Russia - Railway Equipment). In the WTO context Pauwelyn further provides an account of the number of footnotes per AB report. See Paulwelyn (n 17).

143 Richard A Posner, 'Judges' Writing Styles (And Do They Matter?)' (1995) 62 The University of Chicago Law Review 1421, 1427. 144 Consider Posner's analysis of the Brandeis's writing style: Posner, Cardozo (n 17) 44.

145 Consider this example, taken from a scholarly publication and reproduced verbatim:
}

A treaty is a disagreement reduced to writing: Philip Allott, The Health of Nations: Society and Law Beyond the State (2002).

See Philip Allott, Interpretation-An Exact Art (Oxford University Press 2015) 376 <http://www.oxfordscholarship.com/view/10.1093/acprof:oso/9780198725749.001.0001/acprof-9780198725749-chapter-18> accessed 14 December 2018.

146 Jean D’aspremont, 'Wording in International Law' (2012) 25 Leiden Journal of International Law 575, 590; Recall Schlag: ' Legal aesthetics are important because they help constitute law and its possibilities in different ways'. See 'The Aesthetics of American Law' (2002) 115 Harvard Law Review 1047, 1117. 
Naturally, this too is reasoning by proxy: WTO panels and the AB being often extremely lengthy, arguably it is more difficult to expect that all relevant precedents will be addressed in the main text of the decision. Still, running the same type of analysis on a dataset comprised of all available investment decisions on jurisdiction, liability, annulment, and provisional measures returns a total of 37880 citations, of which 11261 remain when footnotes are factored out. Employing an unsophisticated methodology to remove citations in the restatement of parties' pleadings this number is reduced to 6345 citations. These numbers are consistent with anecdotal accounts of a higher degree of engagement with previous decisions in international investment arbitration. In the context of WTO adjudication, instead, what is quite clear is that the level of engagement with previous decisions in the main text has not grown with the average length of the reports. To make but one example, the AB Report in China-GOES contains no citations to precedent in the main text of the decision (beyond those submitted by the parties), even though it is 107 pages long and has 443 footnotes. Including the footnotes in the count, the yield rises to 38 .

\section{B. Quotations, direct speech, and enhancing the text}

A second interesting question concerns the degree to which invocations to are specifically connected to the textual material of the cited precedents. In order to obtain a workable and reasonably accurate metric, citations were collected again, this only including those connected, or shortly following, a phrase delimited by quotation marks. Based on the verbatim repetition of certain paragraphs, a recent study on the ICJ suggests that there is a degree of ritualism in the way a court may use its own precedents. ${ }^{147}$ There is merit to the idea, but the account does not fully capture the relationship between the medium and the message.

It is submitted here that the use of quotations should be taken into account as a symptom of increased attachment to the text, rather than the conclusion, of a given decision - in short, a textualized reading of international precedents. ${ }^{148}$ The point matters because it is not so much a question of repetition of authority: it is a question of using a specific decision with little or no further commentary, ${ }^{149}$ and simultaneously claiming that its text serves its purpose without the need of further interpretation. ${ }^{150}$ To the extent that it is workable, even a 'decorative and cultural quote' can help have argumentative value, 'avoid[ing] preventively the commitment to a specific content, as the burden of defending or supporting it is shifted onto the quoted party'. ${ }^{151}$

The results are particularly striking in the case of the ICJ and the $A B$, where the number of such citations is 1364 and 3065, about half and a quarter of the entire citation dataset respectively. In both cases, there is a tendency towards an increase of citations of this kind and thus a significant re-use of the text of previous decisions. In turn, this suggest a use of precedent akin to the invocation of rule-like propositions.

\footnotetext{
147 Alschner and Charlotin (n 42) 105.

148 Niccolò Ridi, 'Mirages of an Intellectual Dreamland'? Ratio, Obiter, and the Textualization of International Precedent' (Social Science Research Network 2018) SSRN Scholarly Paper ID $329574820<$ https://papers.ssrn.com/abstract=3295748> accessed 16 February 2019.

149 On the self-protection and potential for semantic instability warranted by laconism, see D'aspremont (n 146) 589.

150 On direct and indirect speech see the landmark works of Donald Davidson, 'Quotation' (1979) 11 Theory and decision 27; Laurence Goldstein, 'Quotation of Types and Other Types of Quotation' (1984) 44 Analysis 1; François Recanati, Oratio Obliqua, Oratio Recta: An Essay on Metarepresentation (MIT Press 2000) in particular Chapter 3. See further, for discussion of the significance of quotations within the legal system, Masson v. New Yorker Magazine, Inc. (501 U.S. 496, 1991), at 497-498 ('[W] here a writer uses a quotation that a reasonable reader would conclude purports to be a verbatim repetition of the speaker's statement, the quotation marks indicate that the author is not interpreting the speaker's ambiguous statement, but is attempting to convey what the speaker said').

151 Fabrizio Macagno and Douglas Walton, Interpreting Straw Man Argumentation: The Pragmatics of Quotation and Reporting (Springer 2017) 10.
} 


\section{Psychometry and the language of precedent}

The availability of large amount of text issued in connection with invocation of precedents provides an opportunity to identify more accurate indicators of the adjudicator's approach to precedent. In order to do so, the choice was made to employ Pennebaker and Francis's Linguistic Inquiry and Word Count (LIWC) software. ${ }^{152}$ Rather than simply determining a 'polarity' measure (as it is done in simple sentiment analysis), the software was developed by social psychologists and employs extensive dictionaries of words. Three features make LIWC unique: first, the dictionary-building process made extensive use of human judges and rigorous testing, with a minimal agreement of $93 \%$ on word qualification. ${ }^{153}$ Second, text is measured across multiple dimensions. Among the many possible, the ones included here, in addition to sentiment, are 'analytical thinking' (reflecting more or less formal, logical, and hierarchical thinking), 'clout' (identifying instances where 'the author is speaking from the perspective of high expertise and is confident'), and authenticity (identifying more 'honest, personal, and disclosing text', or its opposite). ${ }^{154}$ Third, LIWC has withstood the test of empirical research, having been employed for the analysis of legal texts. ${ }^{155}$ Although collective judicial writing is known for striving for impersonality, ${ }^{156}$ random sampling confirmed the accuracy of the software for these purposes. ${ }^{157}$

Figure 22 below provides a graphical representation of the evolution of these dimensions over time in the for the ICJ, the W'TO AB, and investment tribunals. ${ }^{158}$ As it may be expected, propositions supported citations scored highly for analytical marks, suggesting an effort to apply the precedent to the facts of the instant case. Conversely, the same text snippets scored low on 'authenticity' and feature a neutral sentiment score. This is consistent with the idea that citations to precedent being one of the tools in the adjudicator's toolbox for making the text more impersonal, and portray the speaker as more impartial and objective. ${ }^{159}$ Moreover, the scores are consistent with the use of precedent to output 'rulelike pronouncements' in need of little additional justifications. ${ }^{160}$ Similar interpretations are possible by considering the 'clout' dimension: the average scores are higher than the baseline, suggesting that the use of precedent might serve a justificatory and legitimizing function. Yet, the scores are not abnormally high, suggesting, once again that reliance on precedent is associated confident, but not boastful, tone that furthers the 'rhetoric of inevitability' that adjudicators seek to promote. ${ }^{161}$

152 James W Pennebaker, Martha E Francis and Roger J Booth, 'Linguistic Inquiry and Word Count: LIWC 2001' (2001) 71 Mahway: Lawrence Erlbaum Associates 2001.

153 Yla R Tausczik and James W Pennebaker, 'The Psychological Meaning of Words: LIWC and Computerized Text Analysis Methods' (2010) 29 Journal of Language and Social Psychology 24, 28.

154 Pennebaker, Francis and Booth (n 152) 22.

155 Ryan J Owens and Justin P Wedeking, 'Justices and Legal Clarity: Analyzing the Complexity of U.S. Supreme Court Opinions' (2011) 45 Law \& Society Review 1027; Frank B Cross and James W Pennebaker, 'The Language of the Roberts Court' [2014] Mich. St. L. Rev. 853.

156 Posner, 'Judges' Writing Styles (And Do They Matter?' (n 143) 1429.

157 The scores were also assessed against the baseline of corresponding passages in which citations to precedent were not made.

158 The sample includes all of the passages that were both citing previous decisions (within the same forum) and were longer than 25 words, after excluding the actual citations or text contained in footnotes.

159 Pierre Bourdieu, 'Force of Law: Toward a Sociology of the Juridical Field, The' (1986) 38 Hastings Law Journal 805, 820 ('The neutralization effect is created by a set of syntactic traits such as the predominance of passive and impersonal constructions. These are designed to mark the impersonality of normative utterances and to establish the speaker as universal subject, at once impartial and objective.').

160 Mirjan R Damaska, The Faces of Justice and State Authority: A Comparative Approach to the Legal Process (Yale University Press 1991) 18-23; Jan Komárek, 'Reasoning with Previous Decisions: Beyond the Doctrine of Precedent' (2013) 61 The American Journal of Comparative Law 149, 163.

161 Robert Ferguson, 'The Judicial Opinion as Literary Genre' (2013) 2 Yale Journal of Law \& the Humanities 213 $<$ https://digitalcommons.law.yale.edu/yjlh/vol2/iss1/15> ('We arise to a concept of inevitability, in the critic Kenneth Burke's 

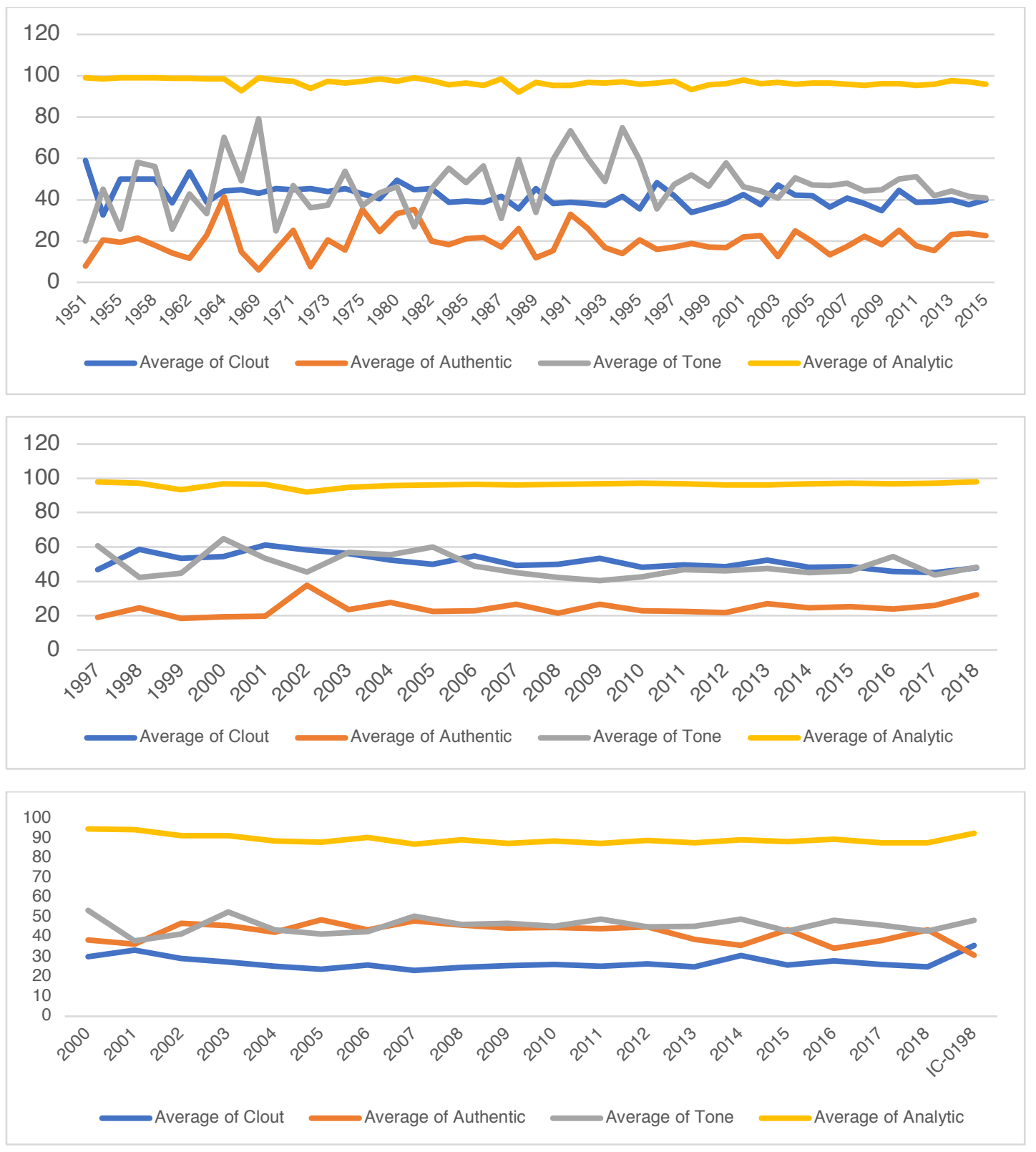

Figure 22

\section{An assessment}

\section{A. Five theses}

This contribution has sought to shed light on the use of precedent by international adjudicators by seeking to lay bare some of the reasons that may lay behind their citation patterns. With the caveat that each part of this article could be developed further, and that more comparison could be found, it is possible to offer a few brief concluding remarks.

use of the term, by seeing present or future things in terms of the past; legal precedents establish just such a relationship by creating an "immutable scene ... of 'eternal truth, equity, and justice'). 


\section{A system of case law?}

The growth in the number of citations, the properties of the citation networks, and the increase in the number of paragraphs cited by international adjudicators provide meaningful evidence of the growing importance of previous decisions - a finding that accords with anecdotal evidence. Contrary to previous studies, the present one does not restrict itself to measuring the frequency and increase in citations, but rather tracks their development beyond a purely bi-dimensional approach. The analysis carried out here goes further, and considers the data in context with comparisons to the examples of a common law court and other jurisdictions that are said to be precedent-driven.

It would be perhaps incautious to argue that a norm of stare decisis operates in international adjudication. ${ }^{162}$ Yet, the findings made here provide strong support for the idea that a doctrine of precedent of some kind might be at play. However strong the evidence, it is sensible to restrict the findings to the conclusion that what is in place is at least a system of case law, that is to say, one where the use of the past, whatever its express qualification, is hardly optional and, indeed, a key tenet of international judicial practice.

\section{Redefining the systemic important of case law: Adjudicators us academics}

A second important conclusion has to do with the systemic importance of case law. It is entirely possible for international adjudicators to fail at the task of determining the ultimate impact of their own output. But it is also possible —and, it is submitted here, quite likely — for other observers to get the picture wrong. International lawyers are, by and large, sensitive to the appeal of the systemic: cases having bearing on systemic issues - sources, interpretation, other fundamental doctrines - are often ready at the fingertips of an academic and act as a fundamental building block in her argumentative toolbox. International adjudicators, it appears, are far less interested in systemic questions_-or in so appearing.

The endless gamut of possible reasons for such differences cannot be explored in detail here. What matters, however, is that citation networks of international adjudicators may well 'revolve' around cases which are not traditionally considered as having high systemic importance. Further, highly-cited—and systemically celebrated-cases may have attracted judicial citations for reasons that are quite distant from those attracting academic references. Thus, it would be wrong to hold that international adjudicators are just concerned with the resolution of concrete problems and moving on to the next case in the docket. Yet, the finding highlights that different concerns are at play, and that adjudicators are more interested in invoking authorities in support, broadly speaking, of their operation, thus portraying their use of the necessary powers as consistent with the past. The internal distribution of citations is key to understanding these dynamics and the general approach taken by international adjudicators in using the past to seek greater legitimacy.

\section{The minimal core of key debates and precedent as an epistemic and legitimizing tool}

Indeed, the internal distribution of citations provides evidence of a second feature of the putative system of case law in question: although many cases stand for more than one simple proposition, the consistent citation of just a few-a phenomenon that is particularly evident within investment arbitration-is symptomatic of the centrality of certain key areas of debate, which can only be loosely identified with the most common causes of action. The hardest and most enduring battles are fought within the narrow constraints of the interpretation and significance of certain key propositions, contained in key paragraphs, rarely abandoned fully, but most commonly employed carefully and artfully by every actor attempting to justify their conduct.

162 Note that such claims have been occasionally made. See Gleider I Hernández, 'A Reluctant Guardian: The International Court of Justice and the Concept of "International Community" [2013] British Yearbook of International Law brt003, 281. 
Nevertheless, 'highly citable' paragraphs tend to have two important qualities: they are epistemically useful, because they contain information that can be reused, very much as a shortcut, to quickly dispose of issues that arise often; ${ }^{163}$ but they are also functionally useful, because they tend to deal with questions that are critical to the operation of the adjudicator concerned, which might, in fact, rely on these material even more when legitimacy is at stake.

\section{4. 'Let us see if it writes': Actors, practices, and their impact}

But, the significance of precedents being established, the analysis carried out here instils some doubts as to who specifically is in charge of the maintenance of their sacred nature. The distribution of citations within the text and the likely delegated nature of the process suggests that, while the directive to ensure coherence might very well originate from the adjudicators themselves, it may nevertheless be executed by bureaucracies and assistants. It does not matter, in this connection, whether the citation of authorities amounts to an expost rationalization of the decision ${ }^{164}$ — a possibility that cannot be discounted in light of anecdotal evidence. ${ }^{165}$ Rather, what matters is that, while the decision to endorse the idea of consistency with the past might be the judges', engagement with it—including, ostensibly, its selection and treatmentmight be the bureaucracies'. Naturally, this has implications, because, as a prominent former Secretary of the ICJ put it, 'the distinction between decision and the expression cannot always be sharply maintained'. ${ }^{166}$

\section{The social component as the key to understanding the authority of precedent}

Finally, contrasting the findings made above to with the corresponding control jurisdictions provide strong evidence that the significance of precedent in international adjudication is not just a product of the specific qualities of the law to be applied or the institutional settings in which the application occurs, but also-and perhaps most crucially - the result of a developing doctrine within the very culture of international and transnational adjudication. This conclusion raises the question of what characteristics-educational, cultural, or otherwise relating to the personal or social qualities of those sitting on the benches of international adjudicators, arguing before them, or even serving as their audience - may be at the basis of these approaches. This is all the more important in light of the uneven distribution of control over international adjudication by a number of exceptionally accomplished professionals. Further research will be needed to investigate these complex areas.

\section{B. Results, limits, and final reflections}

Much of the foregoing analysis has criticised previous attempts to understand the use of precedent by international adjudicators as excessively focused on systemic concerns. It could be argued that the approach indulges in a comparable fallacy, pursuing objectivity by looking at cases as elements in a network governed by mathematical laws of universal applicability—an account that almost certainly differs from how international adjudicators view their own work-and engaging in different species of distant reading. It is readily acknowledged that, as in any experiment, the observer is as responsible for the outcome as is the experienced object. Thus, any data, however neutrally obtained, may be subject to interpretations that follow one's confirmation biases.

Yet, it is submitted that there is value in such an endeavour. Tracking the development of citation networks is but another way to follow the footprints of human activity, divesting oneself-at least momentarily, and not without a suspension of disbelief of sorts — of the doctrinal and discursive constraints that traditionally

\footnotetext{
163 Duxbury (n 8) 92.

164 See Dan Simon, 'A Psychological Model of Judicial Decision Making' (1998) 30 Rutgers LJ 1, 84.

165 Paulsson (n 110) 712 ('Experienced and trusted arbitrators frequently rise from deliberations with the comment

"let us see if it writes").

166 Thirlway (n 90) 215.
} 
inform mainstream analytical approach to questions such as these in the field of international dispute settlement. This contribution makes such an attempt. With no claim to completeness, it strives to provide a map. While it cannot fully describe the entire territory, it is hoped that it will assist its future exploration, thus making the international judicial past less of a foreign country. 